\title{
On The Rate and Extent of Drug Delivery to the Brain
}

\author{
Margareta Hammarlund-Udenaes, ${ }^{1,5}$ Markus Fridén,, ${ }^{1,2}$ Stina Syvänen,, ${ }^{1,3}$ and Anubha Gupta ${ }^{1,4}$
}

Received October 10, 2007; accepted November 12, 2007; published online December 5, 2007

Abstract. To define and differentiate relevant aspects of blood-brain barrier transport and distribution in
order to aid research methodology in brain drug delivery. Pharmacokinetic parameters relative to the
rate and extent of brain drug delivery are described and illustrated with relevant data, with special
emphasis on the unbound, pharmacologically active drug molecule. Drug delivery to the brain can be
comprehensively described using three parameters: $K_{\mathrm{p}, \text { uu }}$ (concentration ratio of unbound drug in brain
to blood), $\mathrm{CL}_{\mathrm{in}}$ (permeability clearance into the brain), and $V_{\mathrm{u} \text {,brain (intra-brain distribution). The }}$
permeability of the blood-brain barrier is less relevant to drug action within the CNS than the extent of
drug delivery, as most drugs are administered on a continuous (repeated) basis. $K_{\mathrm{p}, \text { uu }}$ can differ between
CNS-active drugs by a factor of up to 150 -fold. This range is much smaller than that for log BB ratios
$\left(K_{\mathrm{p}}\right.$ ), which can differ by up to at least 2,000 -fold, or for BBB permeabilities, which span an even larger
range (up to at least 20,000 -fold difference). Methods that measure the three parameters $K_{\mathrm{p}, \text { uu }}, \mathrm{CL}_{\mathrm{in}}$, and
$V_{\mathrm{u}, \text { brain }}$ can give clinically valuable estimates of brain drug delivery in early drug discovery programmes.

KEY WORDS: blood-brain barrier; brain penetration; drug delivery; permeability clearance; unbound concentration.

\section{INTRODUCTION}

For central drug effects to occur, the drug must first be delivered to the brain. Because of the properties of the bloodbrain barrier (BBB), researchers accept a high likelihood of failure when developing drugs for brain delivery $(1,2)$. Methods for investigating drug candidates in this field, from in vitro to in situ and in vivo, are under evaluation (1,3-13). However, confusion remains, and an intense debate is cur-

\footnotetext{
${ }^{1}$ Division of Pharmacokinetics and Drug Therapy, Department of Pharmaceutical Biosciences, Uppsala University, P.O. Box 591, 751 24 Uppsala, Sweden.

${ }^{2}$ Discovery DMPK \& Bioanalytical Chemistry, AstraZeneca R\&D, Mölndal, Sweden.

${ }^{3}$ Uppsala Imanet, GE Healthcare, Uppsala, Sweden.

${ }^{4}$ Clinical Pharmacology, Eisai Clinical Development, Eisai Ltd, 3 Shortlands, London, W6 8 EE, UK.

${ }^{5}$ To whom correspondence should be addressed. (e-mail: mhu@ farmbio.uu.se)
}

ABBREVIATIONS: $A_{\text {tot,brain }}$, Total amount of drug in brain including blood; $A_{\text {brain }}$, Total amount of drug in brain excluding blood; $A_{\text {cell }}$, Total amount of drug associated with brain cells; ABCG2, Breast cancer resistance protein, same as BCRP; $\mathrm{AUC}_{\text {tot,brain, }}$ Area under the curve of total concentrations in brain; $\mathrm{AUC}_{\text {tot,plasma, }}$ Area under the curve of total concentrations in plasma; $\mathrm{AUC}_{\mathrm{u}, \text { brain }}$, Area under the curve of unbound concentrations in brain; $\mathrm{AUC}_{\mathrm{u} \text {,plasma }}$, Area under the curve of unbound concentrations in plasma; BBB, Blood-brain barrier; Bcrp, Breast cancer resistance protein, same as Abcg2; BCSFB, Blood-cerebrospinal fluid barrier; BEI, Brain efflux index; BUI, Brain uptake index; $C_{\text {blood }}$, Total concentrations in whole blood; $C_{\mathrm{i}}$, Concentrations in a hypothetical brain compartment; $C_{\mathrm{u}, \text { cell }}$, Unbound concentration in the brain ICF; $C_{\mathrm{tot}, \mathrm{ss}, \text { brain }}$, Total concentrations in brain rently raging regarding how to interpret the results obtained and which methods to use to select candidates for central nervous system (CNS) action (14-16). The lack of success in this respect to date might be due to a lack of common understanding regarding which processes and properties are most relevant to successful brain drug delivery. In order to interpret in vivo results correctly, the various processes

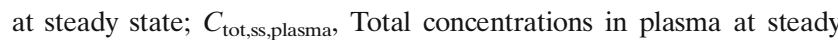
state; $C_{\mathrm{u}, \text { brainISF}}$, Unbound concentrations in brain ISF; $C_{\mathrm{u} \text {,plasma, }}$

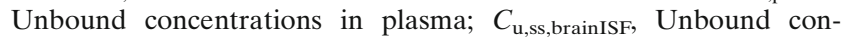
centrations in brain ISF at steady state; $C_{\mathrm{u}, \mathrm{ss} \text {,plasma, Unbound }}$ concentrations in plasma at steady state; $\mathrm{CL}_{\mathrm{i}}$, Intercompartmental clearance; $\mathrm{CL}_{\text {in }}$, Influx clearance into the brain; $\mathrm{CL}_{\text {out }}$, Efflux clearance from the brain; CNS, Central nervous system; CSF, Cerebrospinal fluid; $f_{\mathrm{u} \text {,brain }}$, Fraction unbound drug in brain; $f_{\mathrm{u}, \mathrm{r}}$, Fraction unbound in brain except for ISF (remainder); ICF, Intracellular fluid; ISF, Interstitial fluid, equal to extracellular fluid not including plasma; $K_{\text {in }}$, Brain uptake clearance (iv injection technique); $K_{\text {out }}$, Brain efflux clearance; $K_{\mathrm{p}}$, Total brain/plasma concentration ratio at steady state; $K_{\mathrm{p}, \mathrm{u}}$, Total brain/ unbound plasma concentration ratio at steady state; $K_{\mathrm{p} \text {,uu }}$, Unbound brain/ unbound plasma concentration ratio at steady state; Log BB, Logarithm of the ratio of total steady-state concentration in brain to blood at a given time point; Oatp2, Organic anion transporter peptide 2; Oat3, Organic anion transporter 3; Pgp, P-glycoprotein; PS, Permeability surface area product; $V_{\text {blood }}$, Physiological volume of blood per gram brain; $V_{\mathrm{I}}$, Apparent volume of distribution in a peripheral brain compartment; $V_{\text {ISF, }}$ Physiological volume of brain ISF; $V_{\text {cell }}$, Physiological volume of the brain cells; $V_{\mathrm{u}, \text { brain }}$, Apparent unbound volume of distribution in brain. 
governing drug distribution to the brain must be considered. The present paper therefore addresses the pharmacokinetics of drug transport into, within, and out of the brain.

A basic assumption in pharmacokinetics is that unbound drug concentrations are equal on both sides of a physiological membrane at steady state. The contributions of active influx and/or efflux, and the presence of tight junctions in the membrane, mean that the BBB deviates from this assumption and behaves differently from most other membranes in the body. Metabolism within the CNS, and/or drug transport to the cerebrospinal fluid (CSF) via interstitial fluid (ISF) bulk flow, may also contribute to differing unbound drug concentrations on each side of the BBB.

It is generally accepted that it is the unbound drug that exerts the physiological effect. The comparative importance of unbound drug concentrations in different brain compartments [ISF or intracellular fluid (ICF)] will depend on where the relevant receptors are situated. If the drug in question is actively transported across the cell membrane, brain ICF concentrations could be expected to differ from brain ISF concentrations. There is currently no direct method of studying intracellular unbound drug concentrations in the brain parenchyma, although an indirect method has recently been presented (4).

The more permeable the BBB is to the drug, the quicker the drug will reach the brain tissue. But it is not permeability alone that is important regarding drug delivery to the brain $(5,6,17,18)$. The brain pharmacokinetics of a centrally acting drug, and thereby its associated pharmacodynamics, are the result of a combination of influx and efflux processes plus the extent of distribution of the drug within the brain tissue. The rate of delivery (which is dependent on the permeability of the BBB) must be considered separately from the extent of equilibration of the drug across the $\mathrm{BBB}$ and the intra-brain distribution data in order to fully understand brain drug delivery and its consequences for central drug action.

This paper looks at the different aspects of drug delivery to and distribution within the brain, ranging from the basic physiological properties to an outline of the relevant parameters for describing the processes, with examples. The focus of the article is on comparisons between brain tissue and blood, across the BBB, as this is the main surface area for exchanges between these compartments.

\section{BASIC CONCEPTS AND METHODS}

\section{The BBB and Brain Tissue Physiology}

In order to understand drug transport and distribution in the CNS, it is important to have a clear picture of the physiological volumes and flow rates of the brain fluids. Interpretation of experimental results is often not possible without taking these characteristics into account. Table I lists several of the relevant physiological parameters and values from the literature for the rat, as this species is often used in drug discovery and development.

The BBB is not just a passive membrane separating blood from brain parenchyma, but is an active organ with important functions for brain homeostasis and protection. This organ consists of the endothelial cells comprising the capillaries present throughout the brain parenchyma (Fig. 1). The tight junctions form the basis of the mode of action of the BBB. Apart from metabolic functions, there are numerous transporters governing influx and efflux of endogenous and

Table I. Collated Information from the Literature on Physiological Values Relevant to Drug Transport and Distribution in the Rat Brain

\begin{tabular}{|c|c|c|c|}
\hline Property & Value & Measurement & Reference \\
\hline Brain weight & $1.8 \mathrm{~g}$ & Rat $250 \mathrm{~g}$ & (98) \\
\hline Brain water content & $0.788 \mathrm{ml} / \mathrm{g}$ brain & & (99) \\
\hline \multirow[t]{5}{*}{ Brain vascular space } & $14 \pm 1 \mu \mathrm{l} / \mathrm{g}$ brain & Plasma, sucrose space & $(100)$ \\
\hline & $1.3(0.8-2.0) \% v / v$ & Plasma, ${ }^{133 \mathrm{~m}} \mathrm{In}$ space & $(101)$ \\
\hline & $6.4-23.2 \mu \mathrm{l} / \mathrm{g}$ brain & Plasma, sucrose space & (102) \\
\hline & $34 \pm 4 \mu \mathrm{l} / \mathrm{g}$ brain & Blood, hemodilution technique & (103) \\
\hline & $2.67 \pm 0.33 \mu \mathrm{l} / \mathrm{g}$ brain & Blood, microwave fixation & (104) \\
\hline \multirow[t]{3}{*}{ Cerebral blood flow } & $1.44 \pm 14 \mathrm{ml} / \mathrm{min} / \mathrm{g}$ brain & & $(103)$ \\
\hline & $1.01 \pm 0.24 \mathrm{ml} / \mathrm{min} / \mathrm{g}$ brain & & (104) \\
\hline & $0.93 \mathrm{ml} / \mathrm{min} / \mathrm{g}$ brain & & $(105)$ \\
\hline \multirow[t]{2}{*}{ Mean transit time } & $2.8 \pm 0.8 \mathrm{~s}$ & & (106) \\
\hline & $1.41 \pm 0.07 \mathrm{~s}$ & & (103) \\
\hline Brain endothelial cell thickness (BBB) & $200-500 \mathrm{~nm}$ & & $(8,107)$ \\
\hline Surface area of endothelial cells (BBB) & $100 \mathrm{~cm}^{2} / \mathrm{g}$ brain & & $(108)$ \\
\hline Volume of endothelial cells in brain & $0.80 \mu \mathrm{l} / \mathrm{g}$ brain & & $(109)$ \\
\hline Distance between brain capillaries & $50 \mu \mathrm{m}$ & & (2) \\
\hline \multirow[t]{3}{*}{ Brain ISF volume } & $17-20 \% v / v$ & & (110) \\
\hline & $13.5-14.5 \mathrm{ml} / \mathrm{g}$ brain & & (111) \\
\hline & $0.21 \mathrm{ml} / \mathrm{g}$ brain & & (112) \\
\hline \multirow[t]{2}{*}{ Brain ISF bulk flow } & $0.18-0.29 \mu \mathrm{l} / \mathrm{g}$ brain & & $(32)$ \\
\hline & $0.11 \mu \mathrm{l} / \mathrm{g}$ brain & & (31) \\
\hline CSF volume & $250 \mu \mathrm{l}$ & & (113) \\
\hline \multirow[t]{4}{*}{ CSF production rate } & 2.1-5.4 $\mu \mathrm{l} / \mathrm{min} /$ brain & & (114) \\
\hline & $2.9 \mu \mathrm{l} / \mathrm{min} /$ brain & & $(115)$ \\
\hline & $3.7 \pm 0.1 \mu \mathrm{l} / \mathrm{min} /$ brain & & (116) \\
\hline & $2.2 \mu \mathrm{l} / \mathrm{min} / \mathrm{brain}$ & & (117) \\
\hline
\end{tabular}




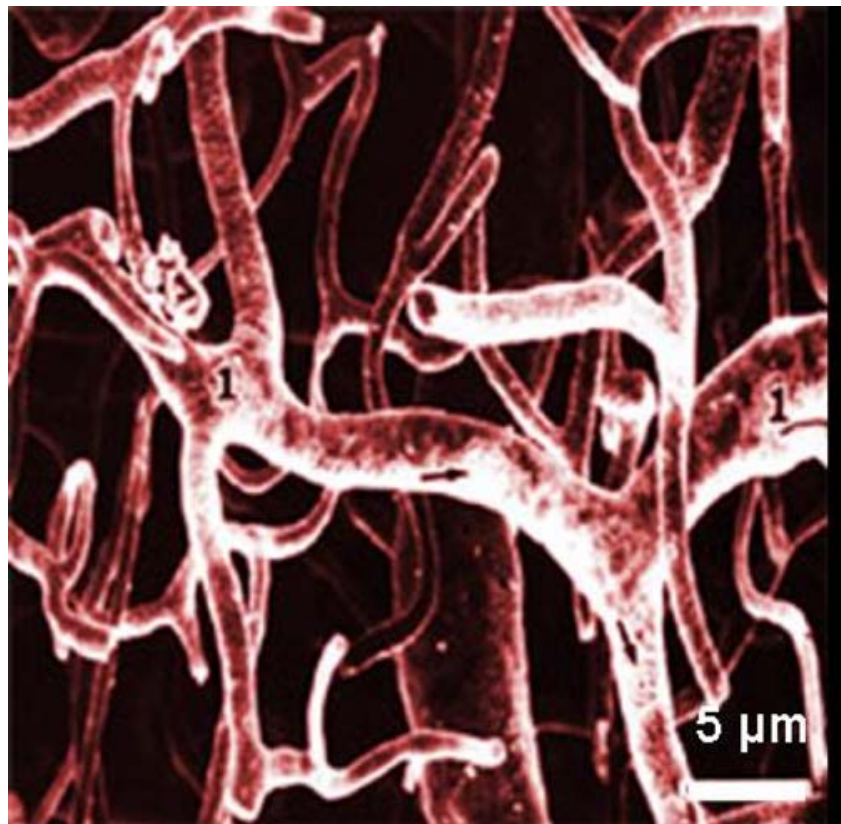

Fig. 1. Brain capillaries from human cerebellar cortex show how close together the brain capillaries forming the blood-brain barrier (BBB) are. From Duvernoy et al. 1983 (119), with permission from the publisher.

exogenous compounds across the BBB (19-24). To transverse the $\mathrm{BBB}$, the compounds need to pass both the luminal (facing blood) and the abluminal (facing brain ISF) membranes of the endothelial cells. For example, the active efflux transporters $P$-glycoprotein (Abcb1, Pgp) and breast cancer resistance protein (Abcg2, Bcrp) are located in the luminal membrane $(25,26)$, while the organic anion transporter 3 (SLC22A8, Oat3) has been found in the abluminal membrane (27), indicating differences in their function. The organic anion transporting polypeptide 2 (SLC01B1, Oatp2) is present in both membranes (28).

Distribution of hydrophilic molecules within the brain involves the tortuous paths associated with diffusion through the ISF, which surrounds the cellular elements, and resultant longer times to equilibrium than would occur in more homogeneous surroundings (Fig. 2) $(29,30)$. Bulk flow of the ISF occurs, especially through the perivascular spaces and axon tracts, draining into the CSF (31-33). CSF is secreted by the choroid plexus into the ventricles, and is drained out through arachnoid villi into the lymphatics. Thus, it is likely that the ISF bulk flow contributes to the passive elimination of drugs from the brain parenchyma. The CSF is separated from the blood by the blood-cerebrospinal fluid barrier (BCSFB) at the choroid plexus epithelium. BCSFB transport is probably of less quantitative importance than BBB transport with regard to the distribution of the majority of drugs into brain tissue and their subsequent effects (34-36). The ependyma lining the ventricles allows diffusional exchange from the CSF to the brain interstitium; however, the contribution of this exchange to the overall distribution of drugs is likely to be small, as it is only diffusional and is counteracted by the bulk flow of brain ISF to the CSF. The diffusion distance from the CSF to most brain tissue is also considerably further than between the brain capillaries. Concurrent transport of a drug across the $\mathrm{BBB}$ is likely to have a dominant effect on brain tissue concentrations after systemic administration, given the large area of the BBB and the short distances between brain capillaries (Fig. 1).

If the $\mathrm{BBB}$ and the $\mathrm{BCSFB}$ are accepted as separate barriers with respect to active drug transport, it cannot be considered relevant to use CSF concentrations as a substitute for brain ISF concentrations without first investigating whether the concentrations and rates of distribution into these compartments are similar $(7,35,36)$. Comparisons between brain ISF and CSF concentrations show that they can indeed differ $(34,35,37)$. It cannot, therefore, be taken for granted that concentrations will be similar, even if this is the case for some drugs. The pragmatic question here is how large these differences in concentration-time relationships between brain ISF and CSF can be while still allowing CSF concentrations to provide a relevant indication of brain ISF concentrations (36).

\section{Pharmacokinetics of Brain Delivery and Distribution of Drugs}

In the blood, drugs are present in the unbound form but may also be bound to plasma proteins and erythrocytes. The free drug hypothesis postulates that the concentration of unbound drug is the driving force for all distribution processes. This implies that plasma protein binding has the role of a bystander regarding distributional and pharmacodynamic steady-state consequences, since it does not influence the extent of transport across the BBB in terms of unbound drug concentrations $(38,39)$. However, since total plasma concentrations are generally used as a reference in pharmacokinetic studies, estimates of plasma protein binding are essential for sound interpretation of pharmacokinetic data, especially when relating the results to the drug pharmacodynamics.

The unbound drug molecules equilibrate across the BBB with those in the brain ISF (Fig. 3). Equilibration between unbound and bound drug molecules also takes place in the interstitial space, across brain cell membranes, and within the cells. Thus, there are several equilibration processes occurring simultaneously and all have an impact on how rapidly steady state is attained between blood and brain concentrations (Fig. 3). The slowest of these equilibrations will be the ratelimiting step for the distribution of a given drug. For drugs

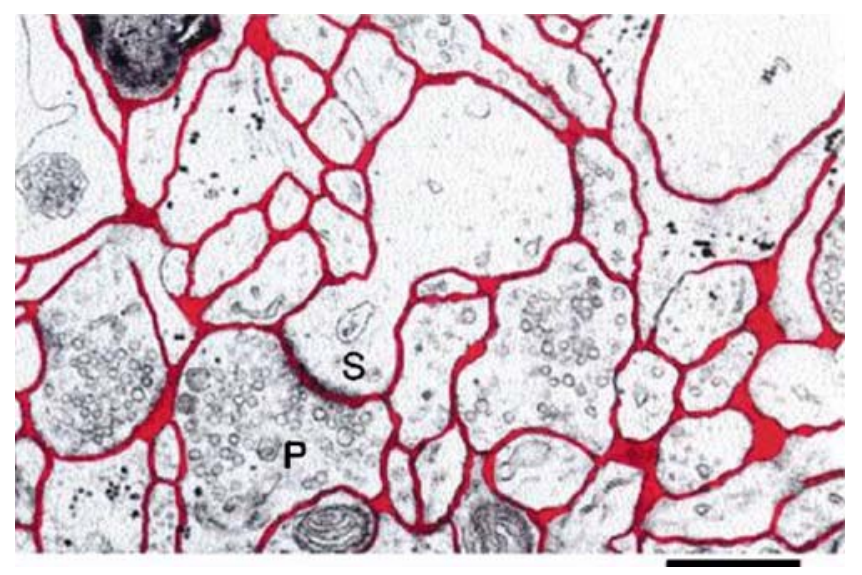

Fig. 2. An electron micrograph of the rat cortex, showing interstitial fluid in red (black in printed version), a dendritic spine (S) and a presynaptic terminal (P). The black bar denotes $1 \mu \mathrm{m}$. From Nicholson and Syková, 1998, with permission from the publisher (29). 

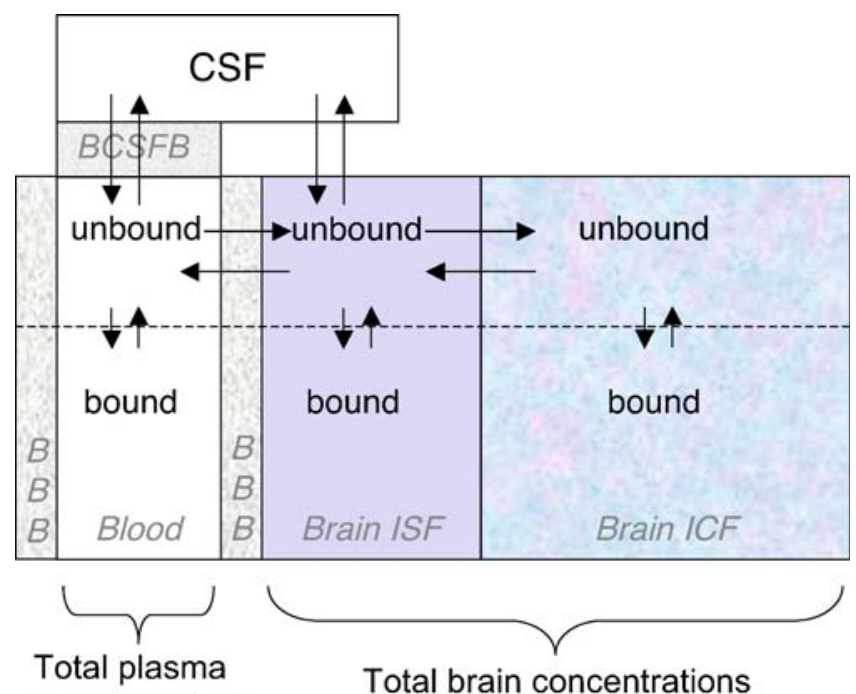
concentrations

Fig. 3. A schematic drawing of the equilibration of drug concentrations among blood, brain and CSF. BBB is the blood-brain barrier, BCSFB is the blood CSF barrier, brain ISF is the brain interstitial fluid and brain ICF is the brain intracellular fluid. Plasma concentrations include both bound and unbound drug, and total brain concentrations include bound and unbound drug both in brain ISF and intracellularly.

associated with low BBB permeability, the rate-limiting step is often the BBB transport itself or the diffusion of drug molecules within brain tissue (40).

The pharmacokinetics of brain delivery are further complicated by active influx and efflux transport at the BBB. The mechanisms by which efflux transporters act will influence the brain pharmacokinetics in different ways $(18,41,42)$. It has been suggested that Pgp, the best known and, according to current understanding, the most important efflux transporter for exogenous substances, lowers brain drug concentrations through two mechanisms: a gate-keeper function that prevents molecules from entering the brain and an extrusion mechanism via which molecules already present in the cytoplasm of the BBB endothelial cells are transported back to the blood (43-46). The effect on the brain concentrationtime profiles will depend on which of these two functions is predominant (42). It has also been speculated that some compounds are transported from the brain ISF into the endothelial cells by abluminal transporters and thereafter by luminal transporters from the BBB to the blood. Hence, transporters located at the two membranes of the BBB may work together to reduce or increase brain concentrations of certain compounds $(27,47)$.

\section{Permeability of the BBB (Rate of Transport)}

The rate of transport of a drug across the BBB is estimated as the permeability surface area product, also called the PS product, or the influx clearance $\left(K_{\text {in }}, \mathrm{CL}_{\text {in }}\right)$. It is measured in $\mu \mathrm{l} \mathrm{min}^{-1} \mathrm{~g}$ brain ${ }^{-1}$ or $\mu 1 \mathrm{~s}^{-1} \mathrm{~g}_{\text {brain }}^{-1}$. These are clearance measurements and not rates per se. In situ and in vivo methods of measuring influx clearances are well established and include, for example, the brain uptake index (BUI; also called the in vivo carotid artery injection technique) (48), the in situ brain perfusion method $(49,50)$, the i.v. injection technique $(51,52)$ and microdialysis (17,53-58). There are several reviews of in situ methods in the literature $(10,59,60)$. Methods like the BUI and in situ brain perfusion are rapid techniques that measure total concentrations of drug in the brain at early time points after drug administration.

Methods for measuring the efflux clearance out of the brain $\left(K_{\text {out }}, \mathrm{CL}_{\text {out }}\right)$ have been developed more recently. These include the brain efflux index (BEI) (61) and combined data from microdialysis and measurements of total brain concentrations using various methods (40,62-70). Efflux parameters based on total brain concentrations alone represent the elimination rate constant (half-life) of the drug in brain parenchyma.
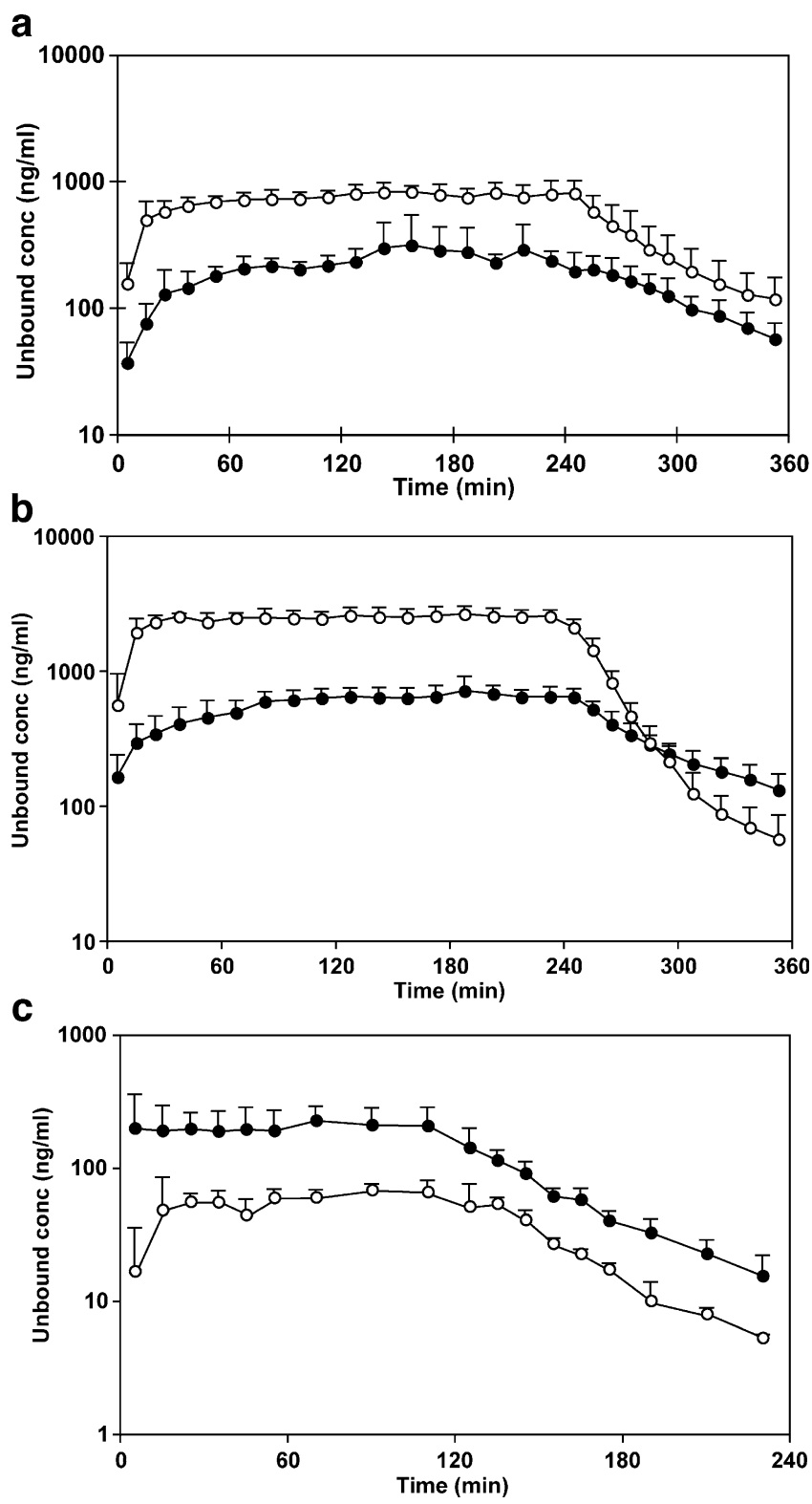

Fig. 4. Blood (empty circles) and brain concentrations (filled circles) of a) unbound morphine, b) unbound $\mathrm{M} 6 \mathrm{G}$ and c) unbound oxycodone in rats. The drugs were administered as exponential infusions over 240 or 120 min to obtain rapid steady state in blood. Microdialysis probes were placed in the jugular vein and striatum. See Table III for values. From Tunblad et al. 2004, 2005 and Boström et al 2006, with permission from the publishers $(68,69,83)$. 
Measurement of influx and efflux clearance with some of these methods requires the researcher to make various assumptions. The intracarotid artery injection, in situ brain perfusion and i.v. injection techniques all involve the assumption that transfer across the $\mathrm{BBB}$ is unidirectional during the study. With the multiple pass methods (in situ brain perfusion and i.v. injection techniques), it is also assumed that BBB penetration itself is the slowest step and that any subsequent distribution processes will be faster. These assumptions are not necessary for microdialysis combined with whole brain tissue concentration measurements at steady state and modeling of the data $(40,67-70)$.

Influx and efflux clearances describe the net capacity of the BBB to transport a substance into or out of the brain. The presence of efflux transporters like Pgp or Abcg2 on the luminal side decreases the permeability (net influx clearance) compared with passive transport, while active influx increases the permeability clearance compared with passive transport $(42,69)$. Elimination via metabolism within the brain is included in the measurement of efflux clearance, as is the contribution of the brain ISF bulk flow.

\section{Extent of Drug Concentration Equilibration between Brain and Blood}

The amount or concentration of drug present in the brain at steady state in relation to that in blood is an important aspect of drug transport to the brain, as it describes centrally acting concentrations over time. Brain concentrations are generally compared with blood concentrations to estimate the delivery of drug to the brain. This ratio can be described by the partition coefficient, $K_{\mathrm{p}}$ :

$$
K_{\mathrm{p}, \text { brain }}=\frac{\mathrm{AUC}_{\text {tot, brain }}}{\mathrm{AUC}_{\text {tot,plasma }}}
$$

where $\mathrm{AUC}_{\mathrm{tot}}$ is the area under the concentration-time curve for total (bound and unbound) concentrations in brain or plasma. AUC and steady-state concentration $C_{\text {ss }}$ can be used interchangeably in this equation as they measure the same property. The value of $K_{\mathrm{p}}$ can vary widely with the rate and extent of BBB transport and the affinity of the drug for brain tissue components relative to plasma protein binding.

To compensate for differences in plasma protein binding, the partition coefficient $K_{\mathrm{p}, \mathrm{u}}$ compares total brain drug concentrations with plasma concentrations of unbound drug:

$$
K_{\mathrm{p}, \mathrm{u}, \text { brain }}=\frac{\mathrm{AUC}_{\text {tot }, \text { brain }}}{\mathrm{AUC}_{\mathrm{u}, \text { plasma }}}
$$

where $\mathrm{AUC}_{\mathrm{u} \text {,plasma }}$ represents the $\mathrm{AUC}$ for unbound drug in plasma, equal to $f_{\text {u,plasma }}$ * $\mathrm{AUC}_{\text {tot,plasma }}$, where $f_{\text {u,plasma }}$ is the fraction of unbound drug in plasma. $K_{\mathrm{p}, \mathrm{u}}$ includes both BBB transport properties and the brain tissue affinity. Thus, for both $K_{\mathrm{p}}$ and $K_{\mathrm{p}, \mathrm{u}}$, all drug present in the brain tissue is included in the relationship, irrespective of whether it is located intra- or extracellularly, or is bound or unbound (Fig. 3).

The pharmacologically active drug component and its equilibration across the BBB can be investigated by measuring unbound drug concentrations in the brain ISF (Fig. 3). The ratio of unbound drug concentration in brain ISF to that in blood is called the unbound partition coefficient $\left(K_{\mathrm{p}, \mathrm{uu}}\right)$. It is independent of protein binding in blood or binding to brain tissue components (71).

$$
K_{\mathrm{p}, \text { uu,brain }}=\frac{\mathrm{AUC}_{\mathrm{u}, \text { brainISF }}}{\mathrm{AUC}_{\mathrm{u}, \text { plasma }}}
$$

The brain ISF concentration, $C_{\mathrm{u} \text {,brainISF, is by definition a }}$ measure of unbound drug. It can be described by:

$$
\begin{aligned}
\frac{V_{\mathrm{ISF}} * d C_{\mathrm{u}, \text { brainISF }}}{\mathrm{d} t}= & \mathrm{CL}_{\mathrm{in}} * C_{\mathrm{u}, \text { plasma }} \\
& -\left(\mathrm{CL}_{\mathrm{out}}+\mathrm{CL}_{\mathrm{i}}\right) * C_{\mathrm{u}, \text { brainISF }}+\mathrm{CL}_{\mathrm{i}} * C_{i}
\end{aligned}
$$

$$
\frac{V_{i}^{*} \mathrm{~d} C_{i}}{\mathrm{~d} t}=\mathrm{CL}_{\mathrm{i}} *\left(C_{\mathrm{u}, \text { brainISF }}-C_{i}\right)
$$

where $V_{\text {ISF }}$ is the physiological volume of brain ISF. Given that more than one compartment is needed to pharmacokinetically describe brain concentration time profiles, $V_{i}$ and $\mathrm{C}_{i}$ are the apparent volume and concentration, respectively, of a peripheral compartment $i$, and $\mathrm{CL}_{\mathrm{i}}$ is the inter-compartmental clearance $(40,67-69,72)$.

At steady state, $\mathrm{d} C_{\mathrm{u}, \text { brainISF }} / \mathrm{d} t=0$. If $C_{\mathrm{u} \text {,brainISF }}=C_{i}$, which can be assumed since $C_{i}$ describes a hypothetical compartment, the relationship in Eq. 4 becomes:

$$
\mathrm{CL}_{\mathrm{in}} * C_{\mathrm{u}, \mathrm{ss}, \text { plasma }}=\mathrm{CL}_{\mathrm{out}} * C_{\mathrm{u}, \mathrm{ss}, \text { brainISF }}
$$

The unbound partition coefficient $K_{\mathrm{p} \text {,uu }}$ is thus determined only by the net influx and efflux clearances $\mathrm{CL}_{\text {in }}$ and $\mathrm{CL}_{\text {out }}$, and not by any subsequent partitioning into brain cells:

$$
K_{\mathrm{p}, \text { uu,brain }}=\frac{\mathrm{AUC}_{\mathrm{u}, \text { brainISF }}}{\mathrm{AUC}_{\mathrm{u}, \text { plasma }}}=\frac{\mathrm{CL}_{\mathrm{in}}}{\mathrm{CL}_{\mathrm{out}}}
$$

The unbound drug concentration ratio between brain ISF and blood at steady state $\left(K_{\mathrm{p}, \mathrm{uu}}\right)$ gives a direct quantitative description of how the $\mathrm{BBB}$ handles the drug regarding passive transport and active influx/efflux. This ratio is determined by the relationship between the influx and efflux clearances, according to Eq. 7. $\mathrm{CL}_{\text {in }}$ is the sum of all passive and active influx clearances minus possible active efflux clearances. $\mathrm{CL}_{\text {out }}$ is, as mentioned earlier, the sum of all elimination clearances from the brain, passive and active BBB transport, and possible metabolism and elimination via the ISF bulk flow. If the relationship is to describe $\mathrm{BBB}$ transport as such, the assumptions are made that the drug is not eliminated to a significant degree by metabolism within the CNS and that it is not transported via bulk flow to the CSF. If these elimination pathways are quantitatively important, $K_{\mathrm{p}, \text { uu }}$ still describes the in vivo steady-state ratio, but cannot be used to determine BBB transport parameters.

If the $\mathrm{BBB}$ transport of a drug is dominated by passive processes, the influx and efflux clearance rates will be similar, with a resulting $K_{\mathrm{p} \text {,uu }}$ close to unity (Eq. 7 ). When a drug is actively effluxed, $\mathrm{CL}_{\text {out }}$ is larger than $\mathrm{CL}_{\mathrm{in}}$, and $K_{\mathrm{p} \text {,uu }}$ becomes smaller than unity. When transport is dominated by active influx, $K_{\mathrm{p} \text {,uu }}$ is larger than unity $(17,18,69,73)$. The equilibration process between brain ISF and brain parenchymal cells has its own rate (Fig. 3). If this process is the slowest step, the time to equilibrium between brain ISF and blood will be longer than if BBB transport is the rate-limiting step $(5,42)$. 
Distribution within the Brain Tissue, $V_{u \text {,brain }}$ and $f_{u, \text { brain }}$

The ratio of concentrations of drug in whole brain tissue to those of unbound drug in brain ISF will vary according to the affinity of the drug for brain tissue components. The unbound drug volume of distribution in brain $\left(V_{\mathrm{u}, \text { brain }}\right)$ is a useful measure of drug distribution in the brain parenchyma since it describes the relationship between the total drug concentration in the brain and the unbound drug concentration in brain ISF. $V_{\mathrm{u} \text {,brain }}$ is measured in $\mathrm{ml} \mathrm{g}$ brain $^{-1}(61,63)$ :

$$
V_{\mathrm{u}, \text { brain }}=\frac{A_{\text {tot }, \text { brain }}-V_{\text {blood }} * C_{\text {tot,blood }}}{C_{\mathrm{u}, \text { brainISF }}}
$$

where $A_{\text {tot,brain }}$ is the measured total amount of drug per $\mathrm{g}$ brain including blood present in the brain, $V_{\text {blood }}$ is the volume of blood per g brain, and $C_{\text {tot,blood }}$ is the total concentration of drug in blood. Compensation for the amount of drug present in brain capillaries increases in importance as the ratio of total drug concentrations in brain to blood decreases (74). The estimated vascular space in brain tissue depends on the vascular marker used (Table I).

Distribution into brain tissue can be experimentally determined in two ways. Equation 8 can be used for data from microdialysis studies at steady state when both unbound brain ISF and total brain drug concentrations are measured, or using AUC values after a shorter infusion. The unbound volume of distribution may also be estimated in vitro in brain slice uptake studies $(4,61)$. In this method, the brain tissue slice is incubated at $37^{\circ} \mathrm{C}$ in an oxygenated buffer containing the substance of interest. Concentration measurements are thereafter made in the buffer (comparable to $C_{\mathrm{u}, \text { brainISF }}$ in Eq. 8 and in the slice (giving $A_{\text {brain }}$, i.e. the amount in brain excluding capillary blood content).

$V_{\mathrm{u} \text { brain }}$ describes the distribution of drug inside the $\mathrm{BBB}$, irrespective of the brain to blood concentration ratio. It is different from the so-called brain volume of distribution calculated in the in situ brain perfusion or i.v. injection techniques, which is defined as the concentration in brain tissue at decapitation divided by the concentration in the perfusion fluid or plasma $(50,52)$. This latter definition of volume of distribution is also used in positron emission tomography (PET). In the present paper, the volume parameter used in in situ brain perfusion and PET techniques is comparable to $K_{\mathrm{p}}$.

Equations describing the physiological components of $V_{\text {u,brain }}$ and how they influence its numerical value can be derived from the definition of $V_{\mathrm{u} \text {,brain }}$ (Eq. 8). If $A_{\text {brain }}$ describes the total amount of drug in blood-free brain tissue, Eq. 8 can be reduced to:

$$
V_{\mathrm{u}, \text { brain }}=\frac{A_{\text {brain }}}{C_{\mathrm{u}, \text { brainISF }}}
$$

where $A_{\text {brain }}$ ( $\mu$ mol g brain $^{-1}$ ) comprises the amount of unbound drug in the ISF plus the amount of drug associated with the cells:

$$
A_{\text {brain }}=V_{\text {brainISF }} \times C_{\mathrm{u}, \text { brainISF }}+V_{\text {cell }} \times A_{\text {cell }}
$$

$V_{\text {brainISF }}$ and $V_{\text {cell }}$ are the physiological fractional volumes of the brain ISF and brain cells, respectively, in $\mathrm{ml} \mathrm{g}$ brain $^{-1}$, and $A_{\text {cell }}$ is the amount of drug associated with the cells $\left(\mu \mathrm{mol} \mathrm{ml} \mathrm{cell}{ }^{-1}\right)$. The distribution volume of unbound drug in the cell, $V_{\text {u,cell }}\left(\mathrm{ml} \mathrm{ICF} \mathrm{ml} \mathrm{cell}{ }^{-1}\right)$ is also introduced, as this relates $A_{\text {cell }}$ to the intracellular concentration of unbound

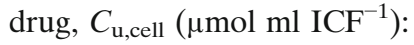

$$
A_{\text {cell }}=V_{\mathrm{u}, \text { cell }} \times C_{\mathrm{u}, \text { cell }}
$$

Incorporating Eq. 11 into Eq. 10 and dividing by $C_{\mathrm{u}, \text { brainISF }}$ gives:

$$
V_{\mathrm{u}, \text { brain }}=V_{\text {brainISF }}+V_{\text {cell }} \times V_{\mathrm{u}, \text { cell }} \times \frac{C_{\mathrm{u}, \text { cell }}}{C_{\mathrm{u}, \text { brainISF }}}
$$

As can be observed in Eq. 12, if no drug binds to or enters the brain parenchyma, $C_{\mathrm{u} \text {,cell }}$ is zero and $V_{\mathrm{u} \text {,brain }}$ becomes equal to $V_{\text {ISF, }}$ typically a value around $0.2 \mathrm{ml} \mathrm{g}$ brain $^{-1}$ (Table I). From a physiological perspective, this is the smallest $V_{\text {u,brain }}$ possible. A value close to the brain water volume $(0.8 \mathrm{ml} \mathrm{g}$ brain $^{-1}$, Table I) may indicate even distribution through the whole brain tissue. Likewise, a $V_{\mathrm{u} \text {,brain }}$ larger than 0.8 indicates that the drug has affinity to brain tissue. Thus, $V_{\mathrm{u} \text {,brain }}$ is a measure of brain distribution that can be compared with physiological volumes to improve understanding of how the drug is distributed in and binds to brain tissue.

The fraction of unbound drug in the brain $\left(f_{\mathrm{u}, \text { brain }}\right)$ can be used in a manner similar to $V_{\mathrm{u} \text {,brain }}(3,7,12,75)$. It originates from the perception that drug distribution within the brain is largely dominated by nonspecific binding, which can be determined by a brain homogenate binding technique (5, 75-77). The parameter $f_{\mathrm{u}, \text { brain }}$ is therefore the fraction of unbound drug in (undiluted) brain homogenate. The in vivo interpretation in terms of actual unbound drug concentrations in ISF is difficult since the intact brain has distinct compartments i.e. the intra- and extracellular spaces. If, but only if, the intra- and extracellular concentrations of unbound drug are the same, the fraction of unbound drug in brain homo-

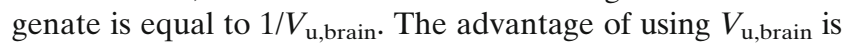
that it can be compared with physiological volumes and thereby give a more realistic insight into drug distribution within the brain.

It cannot be directly assumed that the concentration of unbound drug in brain ISF equals that in brain ICF, as there are also transporters in the brain parenchymal membranes (24). A concentration gradient should in fact be expected for basic and acidic drugs since the lower intracellular $\mathrm{pH}$ initiates trapping processes. It is currently not possible to directly measure intracellular unbound drug concentrations, but indirect techniques are emerging from the combined use of brain slice uptake experiments and binding studies in homogenised brain (4). Because of the absence of plasma proteins in the brain ISF and the small fraction of membrane surface area that faces the ISF, drug binding in brain tissue can be considered intracellular. Accordingly, the brain homogenate binding method measures intracellular binding and allows $V_{\mathrm{u}, \text { cell }}$ to be estimated. When combined with $V_{\mathrm{u} \text {,brain, }}$ from brain slice uptake methods, the ICF-to-ISF concentration ratio of unbound drug $\left(K_{\mathrm{p}, \text { uu,cell }}\right)$ can be calculated as:

$$
K_{\mathrm{p}, \mathrm{uu}, \text { cell }}=\frac{C_{\mathrm{u}, \text { cell }}}{C_{\mathrm{u}, \text { brainISF }}}=\frac{V_{\mathrm{u}, \text { brain }}-V_{\text {brainISF }}}{V_{\text {cell }} \times V_{\mathrm{u}, \text { cell }}}
$$


If the total amount of drug in the brain has been obtained from an in vivo experiment, the unbound intracellular concentration can be similarly estimated:

$$
C_{\mathrm{u}, \text { cell }}=\frac{A_{\text {brain }}\left(V_{\mathrm{u}, \text { brain }}-V_{\text {brainISF }}\right)}{V_{\text {cell }} \times V_{\mathrm{u}, \text { cell }} \times V_{\mathrm{u} \text {,brain }}}
$$

However, it should be remembered that this represents the overall concentration of unbound drug in the ICF and that individual values may differ between different cell types or subcellular structures.

\section{Half-Life in Brain}

If one brain compartment is assumed, the half-life of a drug in brain can be determined by the efflux clearance plus the volume of distribution of unbound drug in the brain, as for half-life calculations in the body. If elimination from the brain is more rapid than elimination from plasma, the plasma half-life will determine the half-life in the brain. If elimination from the brain is slower than from plasma, the brain half-life will be longer. As the brain is such a small part of the whole body, and therefore will retain only a small percentage of the total body concentrations, slow elimination processes in the brain will influence blood pharmacokinetics to a limited extent only. However, as the time from drug administration increases, the blood half-life could theoretically be influenced by a longer brain half-life as the respective contribution from brain elimination increases.

A brain half-life that is longer than the systemic half-life could also influence the value of the partition coefficient of the drug in brain to that in blood, depending on the time of measurement (78). It may be difficult to know when pseudosteady state has been reached after rapid drug administration. Ideally, an infusion should be administered with an initial bolus dose to find the relationship describing steady-state partitioning into the brain.

Active efflux using the gate-keeper mechanism will not alter the drug kinetics inside the brain; it only reduces the number of molecules entering the brain $(41,42)$. Inhibition of a gate-keeper transporter will therefore not change the brain half-life compared to when the gate-keeper mechanism is active. On the other hand, inhibition of a transporter that picks drug molecules from the endothelial cells or brain ISF and transports them back to the blood will result in longer half-lives in the brain. Inhibition experiments can therefore give an indication of the dominant type of active efflux mechanism at the BBB. This assumes that BBB transport, and not intra-brain distribution or elimination from the body, is the rate-limiting step.

\section{Interaction Potential at the $B B B$}

The potential change in brain concentrations due to drug interactions at the $\mathrm{BBB}$, or interaction potential, can be measured quantitatively. The more efficient the efflux, the greater is the potential for a clinically relevant interaction. Quantification requires measurement of $K_{\mathrm{p} \text {,uu }}$ or a corresponding parameter $(4,71,79)$.

The size of the interaction potential is given by the inverse of $K_{\mathrm{p}, \mathrm{uu}}$. If no active transport takes place at the BBB, there is no risk of interactions at this site and the "baseline" value is 1 , i.e. unbound drug concentrations in brain ISF and blood are equal. The lower the $K_{\mathrm{p} \text {,uu }}$, the higher the interaction potential. A $K_{\mathrm{p}, \mathrm{uu}}$ of 0.5 indicates a maximal two-fold increase in brain ISF concentrations if all active efflux is blocked and a ratio of 0.1 will theoretically give a 10 -fold increase. The risk of a drug interaction at the $\mathrm{BBB}$ is also increased if one transporter dominates the transport. As with drug metabolism, if there are several transporters acting on the drug there is less risk of clinical consequences if one of the transporters is blocked. If a drug is actively transported into the brain, the interaction works in the other direction, i.e. decreased brain delivery of the drug when the influx transporter is inhibited. If a drug is a substrate for both influx and efflux transporters, the interaction potential for each transporter is greater than indicated by the $K_{\mathrm{p} \text {,uu }}$ ratio.

The implications of a specific active efflux transporter in this respect have been studied by Dagenais et al. (79). They investigated the "Pgp effect", which describes the reduction in permeability clearance in Pgp-deficient mice compared with that in wild-type mice. This quantifies the impact of the knocked-out transporter on the permeability clearance and is a good measurement of the interaction potential for a specific transporter, as long as the other transporters affecting the drug are not upregulated.

The techniques used to study the interaction potential can influence the result. Changes in permeability clearance in studies of in situ brain perfusion in Pgp knock-out mice will be the same as those estimating $K_{\mathrm{p} \text {,uu }}$ from unbound steadystate ratios when the efflux is achieved with a gate-keeper mechanism. The reason for this is that the gate-keeper mechanism only affects the net influx clearance, i.e. the same parameter that is measured to determine the Pgp effect (79). However, the two methods will not give the same result if active extrusion of molecules from the brain is inhibited, since this mechanism will also affect the net efflux clearance, causing $K_{\mathrm{p} \text {,uu }}$ and the Pgp effect to be influenced to different extents (42).

\section{EXPERIMENTAL FINDINGS IN RELATION TO BASIC CONCEPTS}

The purpose of this section is to illustrate the consequences of different types of measurements on interpretation of the results. Most of the experimental results are from studies of opioids, as this group of drugs has been studied extensively using several of the brain transport methods reviewed here.

\section{Permeability (Rate)}

BBB permeability clearances of the various opioids span almost a 20,000-fold range (Table II), which is nearly as wide as that reported for drugs in general (80). Results using microdialysis and in situ methods based on total brain concentrations seem to be similar for the few drugs for which both methods have been used. Various conclusions can be drawn from these data. Oxycodone has the highest permeability clearance rate $\left(1910 \mu \mathrm{l} \mathrm{ml}^{-1} \mathrm{~g}\right.$ brain $\left.^{-1}\right)$ while M3G has the lowest $\left(0.11 \mu \mathrm{ml}^{-1} \mathrm{~g}_{\text {brain }}^{-1}\right)$. Most opioids have higher permeability clearances than morphine. Although it is a 
Table II. Permeability Clearances of Drugs at the Blood-Brain Barrier in Decreasing Order, Determined Using Different Methods

\begin{tabular}{|c|c|c|c|c|}
\hline Drug & Permeability clearance $\left(\mathrm{CL}_{\text {in }}\right) \mu 1 \mathrm{~min}^{-1}$ brain $^{-1}$ & Method & Species & Reference \\
\hline Oxycodone & 1910 & Microdialysis & Rat & $(69)$ \\
\hline Fentanyl & $1840 \pm 240$ & In situ brain perfusion & Mice & (79) \\
\hline Methadone & $417 \pm 58$ & In situ brain perfusion & Mice & (79) \\
\hline Loperamide & $98.6 \pm 17.3$ & In situ brain perfusion & Mice & $(79)$ \\
\hline Gabapentin & $44 \pm 21$ & Microdialysis & Rat & $(63)$ \\
\hline \multirow[t]{4}{*}{ Morphine } & $8.03 \pm 0.28$ & i.v. injection technique & Rat & $(118)$ \\
\hline & $14 \pm 1$ & Microdialysis & Rat & $(67)$ \\
\hline & $11.4(9)$ & Microdialysis & Rat & $(83)$ \\
\hline & $10.4 \pm 3$ & In situ brain perfusion & Mice & (79) \\
\hline Baclofen & $1.57 \pm 0.76$ & Microdialysis & Rat & (65) \\
\hline \multirow[t]{4}{*}{ M6G } & $0.11 \pm 0.01$ & i.v. injection technique & Rat & $(100)$ \\
\hline & $0.142 \pm 0.026$ & i.v. injection technique & Rat & (118) \\
\hline & $0.35(28)$ & Microdialysis & Rat & $(72)$ \\
\hline & $1.66(17)$ & Microdialysis & Rat & (68) \\
\hline DPDPE & $0.547 \pm 0.293$ & In situ brain perfusion & Mice & (79) \\
\hline \multirow[t]{2}{*}{ M3G } & $0.11(25)$ & Microdialysis & Rat & $(40)$ \\
\hline & $0.14 \pm 0.02$ & i.v. injection technique & Rat & $(100)$ \\
\hline
\end{tabular}

Values are given as \pm SD or (RSE\%).

peptide, the selective delta opioid receptor agonist DPDPE has a higher influx clearance than M3G. In spite of having rather low influx clearances, it is clear that both morphine and M6G are centrally acting. Loperamide is less active centrally than morphine in spite of a higher permeability clearance across the BBB.

\section{Extent of Equilibration vs Intra-Brain Distribution}

The 10-fold difference in influx clearance between morphine and M6G could indicate that the extent of brain delivery also differs between these drugs. Indeed, if total brain concentrations are measured, this seems to be the case. Morphine has a $K_{\mathrm{p}}$ ratio of 0.74 , while that of $\mathrm{M} 6 \mathrm{G}$ is 0.05 (Table III). As the protein binding of the two compounds in blood is about the same, this difference is carried over into $K_{\mathrm{p}, \mathrm{u}}$. However, the unbound concentration ratio $K_{\mathrm{p} \text {,uu }}$ is similar at about 0.29 (Fig. 4, Table III). How can this be, and what does it mean regarding the pharmacodynamics of morphine and M6G? To interpret these results, the intra-brain distribution of the two substances must be examined more closely. The $V_{\mathrm{u} \text {,brain }}$ for morphine is $1.7-2.4 \mathrm{ml} \mathrm{g}$ brain $^{-1}$, while that for $\mathrm{M} 6 \mathrm{G}$ is $0.2 \mathrm{ml} \mathrm{g}$ brain $^{-1}$ (Table III). This indicates a large difference in the way that the two compounds are handled once they are inside the CNS (Fig. 3). The difference in volume between the drugs can be interpreted to mean that morphine distributes into the cells while M6G is confined more to the ISF of the brain. With respect to pharmacodynamic relationships, since the $\mu$ receptors that are activated by opioids face the brain ISF, the unbound brain ISF concentrations will be more important than those in the cells. When the total brain tissue concentration is measured, the M6G sample will be "diluted" by cells containing relatively less M6G, while the morphine sample will not, as morphine is present intracellularly to a larger extent. Thus, the 10 -fold difference in influx clearance between morphine and M6G will not correlate with the similar extent of equilibration across the $\mathrm{BBB}$ of morphine and $\mathrm{M} 6 \mathrm{G}$.

Other drugs can also be used to illustrate the relationships. The influx clearance of the antiepileptic drug gabapentin is $44 \mu \mathrm{min}^{-1} \mathrm{~g}$ brain ${ }^{-1}$. Its $K_{\mathrm{p} \text {,uu }}$ is 0.12 , demonstrating a high proportion of active efflux transport (Table III). Once

Table III. Extent of Equilibration Across the BBB and Intra-Brain Distribution of Drugs in the Rat

\begin{tabular}{|c|c|c|c|c|c|}
\hline Drug & $K_{\mathrm{p}, \text { brain }}$ & $K_{\mathrm{p}, \mathrm{u}, \text { brain }}$ & $K_{\mathrm{p}, \text { uu,brain }}$ & $V_{\mathrm{u}, \text { brain }} \mathrm{ml} \mathrm{g}$ brain $^{-1}$ & Reference \\
\hline Baclofen & & 0.037 & 0.022 & $0.82 \pm 0.56$ & $(65)$ \\
\hline Codeine & $4.0 \pm 1.0$ & & $1.06 \pm 0.12$ & 3.6 & (82) \\
\hline Gabapentin & 0.64 & & 0.12 & 5.5 & (63) \\
\hline \multirow[t]{2}{*}{ Morphine } & $0.54 \pm 0.065$ & $0.65 \pm 0.093$ & $0.29 \pm 0.07$ & 1.7 & (83) \\
\hline & 0.74 & & $0.51 \pm 0.18$ & $2.35^{a}$ & (37) \\
\hline \multirow[t]{3}{*}{ M6G } & $0.069 \pm 0.011$ & $0.080 \pm 0.013$ & 0.29 & $0.19 \pm 0.04$ & (68) \\
\hline & & & $0.22 \pm 0.09$ & $0.2 \pm 0.02$ & $(72)$ \\
\hline & 0.05 & & $0.56 \pm 0.18$ & $0.13^{a}$ & (37) \\
\hline M3G & & & $0.08 \pm 0.02$ & $0.25 \pm 0.02$ & $(40)$ \\
\hline Oxycodone & $4.5 \pm 2.8$ & $7.8 \pm 1.2$ & $3.03(0.038)$ & $2.20 \pm 0.53$ & (69) \\
\hline YM992 & $71 \pm 11$ & & $1.42 \pm 0.81$ & $375 \pm 159$ & (77) \\
\hline
\end{tabular}

$K_{\mathrm{p}}$ is the partition coefficient describing total brain to total plasma concentration ratios, $K_{\mathrm{p}, \mathrm{u}}$ is the partition coefficient describing total brain to unbound plasma concentration ratios, and $K_{\mathrm{p}, \mathrm{uu}}$ is the partition coefficient describing unbound brain ISF to unbound plasma concentration ratios. $V_{\text {u,brain }}$ is the relationship between total brain and unbound brain ISF concentrations.

${ }^{a}$ Calculated from AUC information in the article. 
inside the brain, gabapentin is extensively distributed in brain tissue, with a $V_{\mathrm{u} \text {,brain }}$ of $5.5 \mathrm{ml} \mathrm{g}$ brain $^{-1}$, resulting in a relatively unimpressive $K_{\mathrm{p}}$ of 0.64 . In fact, most of the drug resides intracellularly in the brain, due to active influx into neuronal cells (4). The level of protein binding in blood is very low (81).

Deguchi et al. showed that the influx clearance of the $\mathrm{GABA}_{\mathrm{B}}$ receptor agonist baclofen was dramatically lower than the efflux clearance (1.6 vs $70 \mu \mathrm{l} \mathrm{min}^{-1} \mathrm{~g}$ brain $^{-1}$ ) (65). The distribution volume of this drug in the brain was $0.82 \mathrm{ml} \mathrm{g}$ brain $^{-1}$, showing even distribution through the brain parenchyma. The authors estimated that the concentration of total baclofen in brain was 27 -fold lower than that of unbound baclofen in plasma.

Codeine, with a $K_{\mathrm{p} \text {,uu }}$ of 1 , appears to have predominantly passive, rapid transport across the BBB. Because of a high affinity with brain tissue components, the $K_{\mathrm{p}}$ of codeine is 4 (Table III). Movement across the $\mathrm{BBB}$ of the antidepressant agent YM992 also seems to be dominated by passive transport. This agent has been reported to have a $K_{\mathrm{p} \text {,uu }}$ of around unity, a $K_{\mathrm{p}}$ of 71 and a $V_{\mathrm{u} \text {,brain }}$ of $375 \mathrm{ml} \mathrm{g}$ brain $^{-1}$ (77). This also indicates that there is theoretically no upper limit for the value of $V_{\text {u,brain }}$.

The high $K_{\mathrm{p}}$ of oxycodone is determined by both its intra-brain distribution ( $V_{\mathrm{u}, \text { brain }}$ is $2.2 \mathrm{ml}^{*} \mathrm{~g}$ brain ${ }^{-1}$ ) and active influx at the BBB (69). Its $K_{\mathrm{p} \text {,uu }}$ of 3 indicates threefold higher influx than efflux clearance, a very unusual finding for a drug.

Enantiomers may also differ regarding their distribution into the brain. Gupta et al. compared the extent of brain distribution for the cetirizine enantiomers (71). The $K_{\mathrm{p}}$ values of 0.22 and 0.04 for $S$ - and $R$-cetirizine could indicate enantioselective brain distribution. However, when the different components of $K_{\mathrm{p}}$ were measured, it was found that the plasma protein binding of cetirizine was stereoselective. Binding in the brain, measured by $V_{\mathrm{u} \text {,brain, was not different }}$ and the cetirizine enantiomers had similar $K_{\mathrm{p}, \mathrm{uu}}$ values, indicating that Pgp in the $\mathrm{BBB}$ handles the enantiomers similarly. Thus, the differences in $K_{\mathrm{p}}$ were solely caused by differing plasma protein binding. Drawing conclusions about stereoselective BBB transport based on $K_{\mathrm{p}}$ values could, therefore, be misleading.

\section{Half-Life}

While the brain ISF and blood half-lives of some drugs are similar [e.g. codeine (82)], the brain ISF half-life of several drugs [e.g. morphine, $\mathrm{M} 6 \mathrm{G}$ and $\mathrm{M} 3 \mathrm{G}$ in rats $(37,40,68$, $72,83,84)$ and morphine in humans and pigs $(85,86)]$ is longer than that in blood. For drugs such as zidovudine which easily permeate the $\mathrm{BBB}$, the brain concentration-time profiles generally parallel the blood concentration-time profiles (87). Also atenolol, a drug that is considered to not permeate the $\mathrm{BBB}$, has parallel concentrations in brain ISF and in blood (88). Oxycodone has similar half-lives in brain ISF and blood, despite a $K_{\mathrm{p} \text {,uu }}$ value that is higher than unity (Fig. 4, 69).

\section{Interaction Potential}

Of the opioids studied using in situ brain perfusion, loperamide and DPDPE had the largest interaction potential, with "Pgp effects" of 10 and 12, respectively. This indicates that, in Pgp-deficient mice, the transport of these drugs into the brain is 10 and 12 times higher than in wild-type mice (79). The associated ratio of 1.2 for morphine indicates a minute risk of interaction with Pgp substrates; morphine is also a substrate for probenecid-sensitive transporters (83). Methadone is in the intermediate range in this respect, with a ratio of 2.6 regarding its possible Pgp interaction (79).

Plasma concentrations of $\mathrm{M} 3 \mathrm{G}$ do not differ at all when the drug is administered with probenecid (40). However, the twofold increase in unbound M3G brain concentrations on addition of probenecid illustrates that in some cases it is not possible to discover local drug interactions without local brain concentration measurements. The 27-fold difference in concentrations of baclofen across the BBB with lower concentrations in brain than in plasma was totally abolished during coadministration of probenecid, indicating the enormous influence of probenecid-sensitive transporters on brain concentrations of baclofen, and thus the very large interaction potential for this drug (65).

The BBB interaction between verapamil and cyclosporin A has a potentially large impact on brain verapamil concentrations, and has been studied using PET (89-92). This example illustrates another issue regarding the risk of clinical drug interactions at the $\mathrm{BBB}$. Cyclosporin A is currently one of the most potent Pgp inhibitors on the market for human use. In spite of this, Hsiao et al. elegantly illustrated that clinical doses of cyclosporin A are much lower than those needed to block Pgp fully at the BBB (90). Therefore, in clinical practice, cyclosporin A can approximately double verapamil brain concentrations in spite of a much higher interaction potential. This does not mean, however, that the interaction risk in other organs can be discarded, as the interaction potential is dependent on the activity of the specific influx and efflux transporters in each organ.

\section{Comparison of "Rate" and "Extent" as Indicators of Brain Drug Delivery}

Given the $\mathrm{CL}_{\mathrm{in}}, K_{\mathrm{p}}$ and $K_{\mathrm{p} \text {,uu }}$ values for pharmacologically active opioids in Tables II and III, the permeability clearances between oxycodone and morphine differ 167fold, the $K_{\mathrm{p}}$ values differ six-fold and the $K_{\mathrm{p} \text {,uu }}$ values differ 10 -fold. When comparing oxycodone and M6G, the permeability clearances differ 1,150 -fold, the $K_{\mathrm{p}}$ values differ 90 fold and the $K_{\mathrm{p}, \mathrm{uu}}$ values differ 10 -fold. The corresponding values for oxycodone and $\mathrm{M} 3 \mathrm{G}$ are a 17,000-fold difference in permeability clearance and a 30 -fold difference in $K_{\mathrm{p} \text {,uu }}$. The differences in permeability clearance and unbound partition coefficients between oxycodone and M3G are probably in the maximal range possible, given the very high permeability of oxycodone and the very low permeability of M3G, and also the dominating active influx of oxycodone and the low $K_{\mathrm{p} \text {,uu }}$ of $\mathrm{M} 3 \mathrm{G}$.

The potential difference in BBB permeability between CNS drugs is thus several orders of magnitude greater than the potential difference in unbound concentration ratios between brain and blood. The possible range of differences between potential CNS drugs in total brain concentrations $\left(K_{\mathrm{p}}\right.$ or $\left.K_{\mathrm{p}, \mathrm{u}}\right)$ is also much greater than for $K_{\mathrm{p}, \mathrm{uu}}$, as lipophilic drugs have a high affinity to brain tissue. A realistic estima- 
tion would be that the unbound ratios of any drug pairs will not differ more than those of oxycodone and $\mathrm{M} 3 \mathrm{G}$. This gives a pharmacologically relevant range of $0.1-3$ for $K_{\mathrm{p} \text {,uu values }}$ (a 30-fold difference) for drugs that are potentially adequately delivered to the brain, given that one compound is actively taken up by the brain at the BBB. If baclofen is included, the range is 150 -fold $(0.02-3)(65)$.

\section{DISCUSSION}

This paper defines the factors of importance for determining and predicting drug delivery to the brain. The purpose of the paper was to demonstrate the firm theoretical and experimental in vivo basis on which informed decisions may be based when designing and testing new drug candidates. The purpose was also to review which parameters are actually measured in in vitro, in situ and in silico methods, the interrelationships of these parameters, and the manner in which they are related to clinically relevant parameters. Distinctions between the various $\mathrm{BBB}$ transport and brain delivery parameters may help to explain why good predictive in vitro models have not yet emerged.

The parameters needed for a full description of delivery of drugs to the brain are 1) the permeability clearance, 2) the extent of equilibrium across the BBB, described by the ratio of unbound concentrations in brain ISF to those in blood $\left(K_{\mathrm{p}, \mathrm{uu}}\right)$, and 3$)$ the intra-brain distribution volume $\left(V_{\mathrm{u} \text {,brain }}\right)$. With these three parameters, a clinically relevant picture of brain drug delivery, covering both the rate and extent, can be obtained.

The permeability clearance and other parallel measurements such as the permeability surface area product (PS) describe the rate of transport or, rather, the net influx clearance across the BBB. This parameter, which can vary $20,000-$ fold or more among drugs (80), is measured in cell culture studies and in situ brain perfusion studies. The permeability of the BBB to a drug is determined mainly by the drug's lipophilicity but is also influenced by the presence of active transport processes at the $\mathrm{BBB}$. If the $\mathrm{BBB}$ is highly permeable to a drug, the drug will be rapidly delivered into the brain. Liu et al., however, showed that rapid brain equilibration is not the same as high BBB permeability, since a higher level of nonspecific binding in the brain due to higher lipophilicity will increase the time to reach equilibrium (5). Whether or not high permeability also results in high enough concentrations for central action depends on the presence of active efflux. Rapid permeation is also not necessarily a prerequisite for a CNS effect, as drugs are in most instances used continuously (6). A good example of an "impossible" CNS drug in this respect is morphine, since permeation through the BBB is low and it is actively effluxed.

The intra-brain distribution volume describes the accumulation of drug inside the brain, or rather the nonspecific binding to brain tissue components in relation to unbound drug in brain ISF. Values reported for $V_{\mathrm{u} \text {,brain }}$ vary between 0.2 and $375 \mathrm{ml} \mathrm{g}$ brain $^{-1}(40,77)$, with a possibility of even higher volumes for very lipophilic compounds, resulting in potential for at least 2,000-fold differences in this parameter between CNS-active drugs. The method recommended for determination of intra-brain distribution is the brain slice technique $(3,4,61)$. $V_{\text {u,brain }}$ can be directly compared on a $\mathrm{ml} \mathrm{g}$ brain $^{-1}$ basis to physiological volumes, thus directly showing affinity and distribution. The fraction of unbound drug in brain $\left(f_{\mathrm{u}, \text { brain }}\right)$, which is usually similar to $1 / V_{\mathrm{u} \text {, brain }}$, is a composite parameter representing intra- and extracellular binding. This parameter is determined using the homogenate method, the validity of which is compromised because cell membranes are not intact (4).

The permeation of a drug through the BBB and its intrabrain distribution are governed by similar physico-chemical properties. It is therefore not surprising that, when rate and extent methods based on total drug concentrations are used to measure a parameter, the results are relatively well correlated. In contrast, the extent of transport as being defined here based on unbound drug concentrations is more determined by the balance of the processes at the BBB and less by i.e. lipophilicity as such. $K_{\mathrm{p} \text {,uu }}$ can demonstrate directly whether active efflux or influx is present, and the quantitative importance of this transport. $K_{\mathrm{p} \text {,uu }}$ can also provide an indication of the interaction potential of a drug. It has thus far been shown to vary between 0.02 and 3, i.e. a 150-fold difference $(65,69,93,94)$. The only possible in vivo method for determining $K_{\mathrm{p} \text {,uu }}$ is microdialysis. In the early phases of drug discovery, a reasonable estimation of $K_{\mathrm{p} \text {,uu }}$ can be obtained from a combination of brain slice measurements to

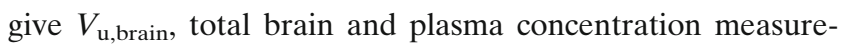
ments at steady state (i.e. after $4 \mathrm{~h}$ of constant infusion), and plasma protein binding measurements (4). Thus, if the extent of $\mathrm{BBB}$ equilibration and the extent of plasma protein binding are known for a drug, a plasma concentration measurement can subsequently be translated into an unbound brain concentration.

Total brain concentrations have historically been the most common method of measuring CNS exposure. Thus, development of a drug might be continued if it has a high brain to plasma concentration ratio. However, high brain concentrations are more an indication of high partitioning into brain tissue than of pharmacologically active drug concentrations. The procedures in early drug discovery programmes may therefore be investigating the wrong targets. Instead of investigating BBB permeability or total brain concentrations, which can differ in value by several orders of magnitude for known CNS drugs, the working range for parameters such as the concentration ratios of unbound drug across the BBB for an active CNS drug will be at most 150fold. $K_{\mathrm{p} \text {,uu }}$ is probably the most relevant parameter for predicting which drugs will be active in the CNS. For example, the extent of BBB equilibration for antihistamines and loperamide is low, thus decreasing their potential for central side effects versus peripheral effects. A high $K_{\mathrm{p} \text {,uu }}$ is preferential when a central effect is desired. Thus, clinically relevant CNS effects may be obtained even though the drug does not permeate the BBB well or is poorly bound to brain tissue (6), or if the protein binding in plasma is high. If there are no peripheral side effects, drugs undergoing extensive efflux could also be considered for central action. If $K_{\mathrm{p} \text {,uu }}$ is low, it is likely to be variable between individuals because of variations in active transporter expression. A low $K_{\mathrm{p} \text {,uu }}$ also show a higher likelihood of drug interactions at the BBB.

$\operatorname{LogBB}$ is often used in in silico models to predict $\mathrm{BBB}$ permeability based on parameters such as the hydrogen bond- 
ing, lipid solubility and molecular weight of the drug. The in vivo $\mathrm{BB}$ value is measured as the brain/blood drug concentration ratio at a specific time point after drug administration (15). According to the definitions in the present paper, $\log B \mathrm{~B}$ is similar to $K_{\mathrm{p}}$ in that it is a measure of the extent of partitioning into brain, but is not necessarily measured at steady state. The parameters measured to obtain in vivo $\log \mathrm{BB}$ values, which are then input into in silico $\log B \mathrm{~B}$ models, include nonspecific binding to brain tissue, BBB equilibration and plasma protein binding. However, BBB permeability, which $\log \mathrm{BB}$ purports to estimate, is not actually measured with this technique. While correlations between $\operatorname{logBB}$ and in vitro or in situ $\mathrm{BBB}$ permeability measurements may be adversely affected because these measurements describe two different aspects of brain drug delivery, both BBB permeability and partitioning into brain tissue are governed by lipophilicity and are therefore correlated with, for example, the solubility of the drug in lipids and its hydrogen bonding properties. It could, therefore, be speculated that $\log \mathrm{BB}$ merely provides an in vivo estimation of lipophilicity rather than the relevant brain distribution estimations, especially in light of the three parameters that are measured to reach $\operatorname{logBB}$. Additionally, the clinical value of a CNS compound is also determined by the presence of active efflux or influx at the BBB. It is therefore apparent that the physico-chemical descriptors currently used in in silico models are not sufficient. Unfortunately, information on transporters other than Pgp that might be quantitatively important at the $\mathrm{BBB}$ is currently rudimentary. What is, however, clear is that several drugs that are not Pgp substrates are poorly transported into the brain $(54,93)$, probably because of active efflux rather than low permeability.

Expressions like "brain penetration" or "CNS penetration" can be defined based on either the rate or extent of penetration. The extent of penetration can refer to either total drug or unbound drug. As shown in the present paper, the rate of penetration differs much more than the extent of penetration between compounds. It has often been said that some compounds are "unable to penetrate the BBB" or have "no brain penetration". In fact, brain penetration can be slow (rate) or low (extent), but there will in most instances be drug present in the brain ISF (17). For example, M6G, which permeates the BBB slowly, has a $K_{\mathrm{p}}$ of 0.05 and a $K_{\mathrm{p} \text {,uu }}$ of 0.27 and is pharmacologically active in the CNS $(37,68,72)$, is illustrative of the problems with using this terminology to understand effective brain drug delivery.

Pardridge suggested that "the BBB PS product predicts the level of free drug in brain, because the level of free drug is determined by: (i) the total drug concentration in plasma; (ii) the PS product; and (iii), in the case of drugs bound by plasma proteins, the fraction of drug in plasma that is bioavailable for transport into brain." (15). However, the PS product per se cannot predict the concentrations of unbound drug in brain, as stated by Pardridge (15) and discussed by Liu and Chen (6). Thus, the PS product cannot alone determine the extent of clinically relevant brain drug delivery. Brain unbound drug concentrations are determined by plasma unbound drug concentrations and $K_{\mathrm{p} \text {,uu }}$, and similar $K_{\mathrm{p} \text {,uu }}$ relationships can occur despite vastly different permeabilities $(17,18)$. It is also apparent that the PS product is a measure of net influx clearance, i.e. its value is influenced by whether the drug is associated with active influx or efflux (79). Studies using knock-out animals can show the influence of a specific transporter, given that the expression of other possible transporters has not changed; however, for many drugs, we do not yet know which transporters to look for.

A high level of plasma protein binding is in itself no limitation for CNS action, as it can in theory be compensated for by using higher doses. Binding to plasma proteins serve as a depot of drug in the plasma. Thus, there is no need to discard otherwise good lead candidates based on a protein binding level above $95 \%$ if other factors appear promising. For example, although diazepam is highly plasma protein bound (15), microdialysis experiments show that it has a $K_{\mathrm{p} \text {,uu }}$ of 1 (38), i.e. unbound drug is distributed evenly between brain ISF and plasma.

It has been suggested that the value of microdialysis is lessened because of its invasive character (15,95-97). However, microdialysis is the only method currently available that can directly measure brain concentrations of unbound drug in vivo. Performed carefully, this method has much to offer in terms of knowledge about BBB transport and the quantitative influence of active transporters on the delivery of drugs to the brain. It is therefore valuable as an in-depth method for following local drug distribution. However, more rapid methods are required in drug discovery programmes $(3,4,6)$. With a combination of in vitro and in vivo methods, it is possible to efficiently map the clinically relevant properties of new compounds, and the development of reliable in silico methods for estimating brain drug delivery is continuing.

\section{CONCLUSIONS}

Relevant in vivo estimations of drug delivery to the brain can be fully described using three parameters: $\mathrm{CL}_{\text {in }}$ to describe the permeability clearance into the brain, $K_{\mathrm{p} \text {,uu }}$ to describe the ratio of unbound drug in brain to that in blood, and $V_{\text {u,brain }}$ to describe the intra-brain distribution. Methods that measure these parameters can give clinically valuable estimates of brain penetration early in the drug discovery process, and can be used to correlate drug distribution with pharmacodynamic evaluations in in vitro or in vivo systems. A combination of measurements is suggested, as a single rapid method cannot map all the important factors. The BBB permeability per se is a less important predictor of drug activity within the CNS than the extent of permeation, as most drugs are administered on a continuous (repeated) basis. Lower BBB permeability indicates slower transport into the brain, but it may also indicate slower removal from the brain. Low permeability issues for a potential drug may be addressed by using dosage forms with slower release characteristics. Among known CNS drugs, the ratio of brain ISF to plasma unbound drug concentrations $\left(K_{\mathrm{p}, \mathrm{uu}}\right)$ can differ by a factor of up to 150 -fold. This range is much smaller than that for $\log \mathrm{BB}$ ratios $\left(K_{\mathrm{p}}\right)$ which can differ by up to at least 2,000-fold, or for BBB permeabilities, which span an even larger range (up to at least 20,000-fold). Thus, we need to rethink the basis on which CNS drugs are selected and realize that the range within which to work may be much smaller than earlier comprehended. It is hoped that this paper will provide inspiration for evidence-based consideration of the choice of methods for determining successful brain penetration. 


\section{REFERENCES}

1. M. R. Feng. Assessment of blood-brain barrier penetration: in silico, in vitro and in vivo. Current Drug Metabolism 3:647-657 (2002).

2. W. M. Pardridge. The blood-brain barrier: bottleneck in brain drug development. NeuroRx 2:3-14 (2005).

3. S. Becker, and X. Liu. Evaluation of the utility of brain slice methods to study brain penetration. Drug. Metab. Dispos. 34:855-861 (2006)

4. M. Fridén, A. Gupta, M. Antonsson, U. Bredberg, and M. Hammarlund-Udenaes. In vitro methods for estimating unbound drug concentrations in the brain interstitial and intracellular fluids. Drug. Metab. Dispos. 35:1711-1719 (2007).

5. X. Liu, B. J. Smith, C. Chen, E. Callegari, S. L. Becker, X. Chen, J. Cianfrogna, A. C. Doran, S. D. Doran, J. P. Gibbs, N. Hosea, J. Liu, F. R. Nelson, M. A. Szewc, and J. Van Deusen. Use of a physiologically based pharmacokinetic model to study the time to reach brain equilibrium: an experimental analysis of the role of blood-brain barrier permeability, plasma protein binding, and brain tissue binding. J. Pharmacol. Exp. Ther. 313:1254-1262 (2005).

6. X. Liu and C. Chen. Strategies to optimize brain penetration in drug discovery. Curr. Opin. Drug Discov. Dev. 8:505-512 (2005).

7. X. Liu, B. J. Smith, C. Chen, E. Callegari, S. L. Becker, X. Chen, J. Cianfrogna, A. C. Doran, S. D. Doran, J. P. Gibbs, N. Hosea, J. Liu, F. R. Nelson, M. A. Szewc, and J. Van Deusen. Evaluation Of cerebrospinal fluid concentration and plasma free concentration as a surrogate measurement for brain free concentration. Drug. Metab. Dispos. (2006).

8. W. M. Pardridge. The blood-brain barrier and neurotherapeutics. NeuroRx 2:1-2 (2005).

9. D. J. Begley. Delivery of therapeutic agents to the central nervous system: the problems and the possibilities. Pharmacol. Ther. 104:29-45 (2004).

10. U. Bickel. How to measure drug transport across the bloodbrain barrier. NeuroRx 2:15-26 (2005).

11. P. Garberg, M. Ball, N. Borg, R. Cecchelli, L. Fenart, R. D. Hurst, T. Lindmark, A. Mabondzo, J. E. Nilsson, T. J. Raub, D. Stanimirovic, T. Terasaki, J. O. Oberg, and T. Osterberg. In vitro models for the blood-brain barrier. Toxicol. in Vitro 19:299-334 (2005).

12. S. G. Summerfield, K. Read, D. J. Begley, T. Obradovic, I. J. Hidalgo, S. Coggon, A. V. Lewis, R. A. Porter, and P. Jeffrey. Central nervous system drug disposition: the relationship between in situ brain permeability and brain free fraction. $J$. Pharmacol. Exp. Ther. 322:205-213 (2007).

13. S. G. Summerfield, A. J. Stevens, L. Cutler, M. del Carmen Osuna, B. Hammond, S. P. Tang, A. Hersey, D. J. Spalding, and $\mathrm{P}$. Jeffrey. Improving the in vitro prediction of in vivo central nervous system penetration: integrating permeability, $\mathrm{P}$ glycoprotein efflux, and free fractions in blood and brain. J. Pharmacol. Exp. Ther. 316:1282-1290 (2006).

14. I. Martin. Prediction of blood-brain barrier penetration: are we missing the point? [see comment] [comment]. Drug Discov. Today 9:161-162 (2004).

15. W. M. Pardridge. $\log (\mathrm{BB})$, PS products and in silico models of drug brain penetration. [comment]. Drug Discov. Today 9:392393 (2004)

16. L. Cucullo, B. Aumayr, E. Rapp, and D. Janigro. Drug delivery and in vitro models of the blood-brain barrier. Curr. Opin. Drug Discov. Dev. 8:89-99 (2005).

17. M. Hammarlund-Udenaes. The use of microdialysis in CNS drug delivery studies. Pharmacokinetic perspectives and results with analgesics and antiepileptics. Adv. Drug Deliv. Rev. 45:283-294 (2000).

18. M. Hammarlund-Udenaes, L. K. Paalzow, and E. C. de Lange. Drug equilibration across the blood-brain barrier-pharmacokinetic considerations based on the microdialysis method. Pharm. Res. 14:128-134 (1997).

19. D. J. Begley. ABC transporters and the blood-brain barrier. Curr. Pharm. Des. 10:1295-1312 (2004).
20. W. Loscher and H. Potschka. Blood-brain barrier active efflux transporters: ATP-binding cassette gene family. NeuroRx 2:8698 (2005).

21. H. Kusuhara and Y. Sugiyama. Active efflux across the bloodbrain barrier: role of the solute carrier family. NeuroRx 2:73-85 (2005).

22. A. Tsuji. Small molecular drug transfer across the blood-brain barrier via carrier-mediated transport systems. NeuroRx 2:5462 (2005).

23. J. M. Scherrmann. Expression and function of multidrug resistance transporters at the blood-brain barriers. Expert Opin. Drug Metab. Toxicol. 1:233-246 (2005).

24. S. Dallas, D. S. Miller, and R. Bendayan. Multidrug resistanceassociated proteins: expression and function in the central nervous system. Pharmacol. Rev. 58:140-161 (2006).

25. A. Tsuji, T. Terasaki, Y. Takabatake, Y. Tenda, I. Tamai, T. Yamashima, S. Moritani, T. Tsuruo, and J. Yamashita. Pglycoprotein as the drug efflux pump in primary cultured bovine brain capillary endothelial cells. Life Sci. 51:1427-1437 (1992).

26. H. C. Cooray, C. G. Blackmore, L. Maskell, and M. A. Barrand. Localisation of breast cancer resistance protein in microvessel endothelium of human brain. NeuroReport 13:2059-2063 (2002).

27. S. Mori, H. Takanaga, S. Ohtsuki, T. Deguchi, Y. S. Kang, K. Hosoya, and T. Terasaki. Rat organic anion transporter 3 (rOAT3) is responsible for brain-to-blood efflux of homovanillic acid at the abluminal membrane of brain capillary endothelial cells. J. Cereb. Blood Flow Metab. 23:432-440 (2003).

28. B. Gao, B. Stieger, B. Noe, J. M. Fritschy, and P. J. Meier. Localization of the organic anion transporting polypeptide 2 (Oatp2) in capillary endothelium and choroid plexus epithelium of rat brain. J. Histochem. Cytochem. 47:1255-1264 (1999).

29. C. Nicholson, and E. Sykova. Extracellular space structure revealed by diffusion analysis. [see comment]. Trends Neurosci. 21:207-215 (1998).

30. C. Nicholson, J. M. Phillips, and A. R. Gardner-Medwin. Diffusion from an iontophoretic point source in the brain: role of tortuosity and volume fraction. Brain Res. 169:580-584 (1979).

31. H. F. Cserr, D. N. Cooper, P. K. Suri, and C. S. Patlak. Efflux of radiolabeled polyethylene glycols and albumin from rat brain Am. J. Physiol. 240:F319-F328 (1981).

32. I. Szentistvanyi, C. S. Patlak, R. A. Ellis, and H. F. Cserr. Drainage of interstitial fluid from different regions of rat brain. Am. J. Physiol. 246:F835-F844 (1984).

33. N. J. Abbott. Evidence for bulk flow of brain interstitial fluid: significance for physiology and pathology. Neurochem. Int. 45:545-552 (2004).

34. T. Ooie, T. Terasaki, H. Suzuki, and Y. Sugiyama. Kinetic evidence for active efflux transport across the blood-brain barrier of quinolone antibiotics. J. Pharmacol. Exp. Ther 283:293-304 (1997).

35. E. C. de Lange, and M. Danhof. Considerations in the use of cerebrospinal fluid pharmacokinetics to predict brain target concentrations in the clinical setting: implications of the barriers between blood and brain. Clin. Pharmacokinet. 41:691-703 (2002).

36. D. D. Shen, A. A. Artru, and K. K. Adkison. Principles and applicability of CSF sampling for the assessment of CNS drug delivery and pharmacodynamics. Adv. Drug Deliv. Rev. 56:1825-1857 (2004).

37. F. Stain-Texier, G. Boschi, P. Sandouk, and J. M. Scherrmann. Elevated concentrations of morphine 6-beta-D-glucuronide in brain extracellular fluid despite low blood-brain barrier permeability. Br. J. Pharmacol. 128:917-924 (1999).

38. R. K. Dubey, C. B. McAllister, M. Inoue, and G. R. Wilkinson. Plasma binding and transport of diazepam across the bloodbrain barrier. No evidence for in vivo enhanced dissociation. J. Clin. Invest. 84:1155-1159 (1989).

39. P. M. Klockowski, and G. Levy. Kinetics of drug action in disease states. XXIV. Pharmacodynamics of diazepam and its active metabolites in rats. J. Pharmacol. Exp. Ther. 244:912-918 (1988).

40. R. Xie, M. R. Bouw, and M. Hammarlund-Udenaes. Modelling of the blood-brain barrier transport of morphine-3-glucuronide 
studied using microdialysis in the rat: involvement of probenecidsensitive transport. Br. J. Pharmacol. 131:1784-1792 (2000).

41. P. L. Golden and G. M. Pollack. Rationale for influx enhancement versus efflux blockade to increase drug exposure to the brain. Biopharm. Drug Dispos. 19:263-272 (1998).

42. S. Syvänen, R. Xie, S. Sahin, and M. Hammarlund-Udenaes. Pharmacokinetic consequences of active drug efflux at the blood-brain barrier. Pharm. Res. (2006).

43. C. F. Higgins and M. M. Gottesman. Is the multidrug transporter a flippase? Trends Biochem. Sci. 17:18-21 (1992).

44. W. D. Stein, C. Cardarelli, I. Pastan, and M. M. Gottesman. Kinetic evidence suggesting that the multidrug transporter differentially handles influx and efflux of its substrates. Mol. Pharmacol. 45:763-772 (1994).

45. F. J. Sharom. The P-glycoprotein efflux pump: how does it transport drugs? [see comment]. J Memb. Biol. 160:161-175 (1997).

46. C. F. Higgins and K. J. Linton. The ATP switch model for ABC transporters. Nat. Struct. Mol. Biol. 11:918-926 (2004).

47. S. Mori, S. Ohtsuki, H. Takanaga, T. Kikkawa, Y. S. Kang, and T. Terasaki. Organic anion transporter 3 is involved in the brainto-blood efflux transport of thiopurine nucleobase analogs. J. Neurochem. 90:931-941 (2004).

48. W. H. Oldendorf. Measurement of brain uptake of radiolabeled substances using a tritiated water internal standard. Brain Res. 24:372-376 (1970).

49. Y. Takasato, S. I. Rapoport, and Q. R. Smith. An in situ brain perfusion technique to study cerebrovascular transport in the rat. Am. J. Physiol. 247:H484-H493 (1984).

50. C. Dagenais, C. Rousselle, G. M. Pollack, and J. M. Scherrmann. Development of an in situ mouse brain perfusion model and its application to mdr1a P-glycoprotein-deficient mice. J. Cereb. Blood Flow Metab. 20:381-386 (2000).

51. K. Ohno, K. D. Pettigrew, and S. I. Rapoport. Lower limits of cerebrovascular permeability to nonelectrolytes in the conscious rat. Am. J. Physiol. 235:H299-H307 (1978).

52. C. S. Patlak, R. G. Blasberg, and J. D. Fenstermacher. Graphical evaluation of blood-to-brain transfer constants from multiple-time uptake data. J. Cereb. Blood Flow Metab. 3:1-7 (1983).

53. H. Benveniste and P. C. Huttemeier. Microdialysis-theory and application. Prog. Neurobiol. 35:195-215 (1990).

54. E. C. de Lange, M. Danhof, A. G. de Boer, and D. D. Breimer. Methodological considerations of intracerebral microdialysis in pharmacokinetic studies on drug transport across the bloodbrain barrier. Brain Res. Brain Res. Rev. 25:27-49 (1997).

55. E. C. de Lange, A. G. de Boer, and D. D. Breimer. Methodological issues in microdialysis sampling for pharmacokinetic studies. Adv. Drug Deliv. Rev. 45:125-148 (2000).

56. E. C. de Lange, B. A. de Boer, and D. D. Breimer. Microdialysis for pharmacokinetic analysis of drug transport to the brain. Adv. Drug Deliv. Rev. 36:211-227 (1999).

57. W. F. Elmquist and R. J. Sawchuk. Application of microdialysis in pharmacokinetic studies. Pharm. Res. 14:267-288 (1997).

58. J. Kehr. A survey on quantitative microdialysis: theoretical models and practical implications. J. Neurosci. Methods 48:251261 (1993).

59. Q. R. Smith. A review of blood-brain barrier transport techniques. Methods in Molecular Medicine 89:193-208 (2003).

60. W. M. Pardridge. Introduction to the Blood-Brain Barrier, Cambridge University Press, Cambridge, 1998.

61. A. Kakee, T. Terasaki, and Y. Sugiyama. Brain efflux index as a novel method of analyzing efflux transport at the blood-brain barrier. J. Pharmacol. Exp. Ther. 277:1550-1559 (1996).

62. Y. Wang and R. J. Sawchuk. Zidovudine transport in the rabbit brain during intravenous and intracerebroventricular infusion. J. Pharm. Sci. 84:871-876 (1995).

63. Y. Wang and D. F. Welty. The simultaneous estimation of the influx and efflux blood-brain barrier permeabilities of gabapentin using a microdialysis-pharmacokinetic approach. Pharm. Res. 13:398-403 (1996).

64. Y. Deguchi, K. Nozawa, S. Yamada, Y. Yokoyama, and R. Kimura. Quantitative evaluation of brain distribution and blood-brain barrier efflux transport of probenecid in rats by microdialysis: possible involvement of the monocarboxylic acid transport system. J. Pharmacol. Exp. Ther. 280:551-560 (1997).

65. Y. Deguchi, K. Inabe, K. Tomiyasu, K. Nozawa, S. Yamada, and R. Kimura. Study on brain interstitial fluid distribution and blood-brain barrier transport of baclofen in rats by microdialysis. Pharm. Res. 12:1838-1844 (1995).

66. Y. Deguchi, Y. Yokoyama, T. Sakamoto, H. Hayashi, T. Naito, S. Yamada, and R. Kimura. Brain distribution of 6-mercaptopurine is regulated by the efflux transport system in the bloodbrain barrier. Life Sci. 66:649-662 (2000).

67. M. R. Bouw, M. Gardmark, and M. Hammarlund-Udenaes. Pharmacokinetic-pharmacodynamic modelling of morphine transport across the blood-brain barrier as a cause of the antinociceptive effect delay in rats-a microdialysis study. Pharm. Res. 17:1220-1227 (2000).

68. K. Tunblad, M. Hammarlund-Udenaes, and E. N. Jonsson. Influence of probenecid on the delivery of morphine-6glucuronide to the brain. Eur. J. Pharm. Sci. 24:49-57 (2005).

69. E. Boström, U. S. Simonsson, and M. Hammarlund-Udenaes. In vivo blood-brain barrier transport of oxycodone in the rat: indications for active influx and implications for pharmacokinetics/ pharmacodynamics. Drug Metab. Dispos. 34:1624-1631 (2006)

70. K. Tunblad, M. Hammarlund-Udenaes, and E. N. Jonsson. An integrated model for the analysis of pharmacokinetic data from microdialysis experiments. Pharm. Res. 21:1698-1707 (2004).

71. A. Gupta, P. Chatelain, R. Massingham, E. N. Jonsson, and M. Hammarlund-Udenaes. Brain distribution of cetirizine enantiomers: comparison of three different tissue-to-plasma partition coefficients: $\mathrm{K}(\mathrm{p}), \mathrm{K}(\mathrm{p}, \mathrm{u})$, and $\mathrm{K}(\mathrm{p}, \mathrm{uu})$. Drug. Metab. Dispos. 34:318-323 (2006).

72. M. R. Bouw, R. Xie, K. Tunblad, and M. HammarlundUdenaes. Blood-brain barrier transport and brain distribution of morphine-6-glucuronide in relation to the antinociceptive effect in rats-pharmacokinetic/pharmacodynamic modelling. Br. J. Pharmacol. 134:1796-1804 (2001).

73. E. Sam, S. Sarre, Y. Michotte, and N. Verbeke. Distribution of apomorphine enantiomers in plasma, brain tissue and striatal extracellular fluid. Eur. J. Pharmacol. 329:9-15 (1997).

74. S. P. Khor, H. Bozigian, and M. Mayersohn. Potential error in the measurement of tissue to blood distribution coefficients in physiological pharmacokinetic modeling. Residual tissue blood. II. Distribution of phencyclidine in the rat. Drug Metab. Dispos. 19:486-490 (1991)

75. T. S. Maurer, D. B. Debartolo, D. A. Tess, and D. O. Scott. Relationship between exposure and nonspecific binding of thirty-three central nervous system drugs in mice. Drug Metab. Dispos. 33:175-181 (2005)

76. J. C. Kalvass and T. S. Maurer. Influence of nonspecific brain and plasma binding on CNS exposure: implications for rational drug discovery. Biopharm. Drug Dispos. 23:327-338 (2002).

77. Y. Mano, S. Higuchi, and H. Kamimura. Investigation of the high partition of YM992, a novel antidepressant, in rat brainin vitro and in vivo evidence for the high binding in brain and the high permeability at the BBB. Biopharm. Drug Dispos. 23:351-360 (2002).

78. R. E. Carson. PET physiological measurements using constant infusion. Nucl. Med. Biol. 27:657-660 (2000).

79. C. Dagenais, C. L. Graff, and G. M. Pollack. Variable modulation of opioid brain uptake by P-glycoprotein in mice. Biochem. Pharmacol. 67:269-276 (2004).

80. V. A. Levin. Relationship of octanol/water partition coefficient and molecular weight to rat brain capillary permeability. J. Med. Chem. 23:682-684 (1980).

81. L. L. Radulovic, D. Turck, A. von Hodenberg, K. O. Vollmer, W. P. McNally, P. D. DeHart, B. J. Hanson, H. N. Bockbrader, and T. Chang. Disposition of gabapentin (neurontin) in mice, rats, dogs, and monkeys. Drug Metab. Dispos. 23:441-448 (1995)

82. R. Xie and M. Hammarlund-Udenaes. Blood-brain barrier equilibration of codeine in rats studied with microdialysis. Pharm. Res. 15:570-575 (1998).

83. K. Tunblad, E. N. Jonsson, and M. Hammarlund-Udenaes. Morphine blood-brain barrier transport is influenced by probenecid co-administration. Pharm. Res. 20:618-623 (2003). 
84. T. A. Aasmundstad, J. Morland, and R. E. Paulsen. Distribution of morphine 6-glucuronide and morphine across the bloodbrain barrier in awake, freely moving rats investigated by in vivo microdialysis sampling. J. Pharmacol. Exp. Ther. 275:435441 (1995).

85. P. Ederoth, K. Tunblad, R. Bouw, C. J. Lundberg, U. Ungerstedt, C. H. Nordstrom, and M. Hammarlund-Udenaes. Blood-brain barrier transport of morphine in patients with severe brain trauma. Br. J. Clin. Pharmacol. 57:427-435 (2004).

86. K. Tunblad, P. Ederoth, A. Gardenfors, M. HammarlundUdenaes, and C. H. Nordstrom. Altered brain exposure of morphine in experimental meningitis studied with microdialysis. Acta Anaesthesiol. Scand. 48:294-301 (2004).

87. S. L. Wong, Y. Wang, and R. J. Sawchuk. Analysis of zidovudine distribution to specific regions in rabbit brain using microdialysis. Pharm. Res. 9:332-338 (1992).

88. E. C. de Lange, M. Danhof, A. G. de Boer, and D. D. Breimer. Critical factors of intracerebral microdialysis as a technique to determine the pharmacokinetics of drugs in rat brain. Brain Res. 666:1-8 (1994).

89. N. H. Hendrikse, E. G. de Vries, L. Eriks-Fluks, W. T. van der Graaf, G. A. Hospers, A. T. Willemsen, W. Vaalburg, and E. J. Franssen. A new in vivo method to study P-glycoprotein transport in tumors and the blood-brain barrier. Cancer Res. 59:2411-2416 (1999).

90. P. Hsiao, L. Sasongko, J. M. Link, D. A. Mankoff, M. Muzi, A. C. Collier, and J. D. Unadkat. Verapamil P-glycoprotein transport across the rat blood-brain barrier: cyclosporine, a concentration inhibition analysis, and comparison with human data. J. Pharmacol. Exp. Ther. 317:704-710 (2006).

91. L. Sasongko, J. M. Link, M. Muzi, D. A. Mankoff, X. Yang, A. C. Collier, S. C. Shoner, and J. D. Unadkat. Imaging P-glycoprotein transport activity at the human blood-brain barrier with positron emission tomography. Clin. Pharmacol. Ther. 77:503-514 (2005).

92. S. Syvännen, G. Blomquist, M. Sprycha, A. U. Hoglund, M. Roman, O. Eriksson, M. Hammarlund-Udenaes, B. Langstrom, and M. Bergstrom. Duration and degree of cyclosporin induced P-glycoprotein inhibition in the rat blood-brain barrier can be studied with PET. Neuroimage 32:1134-1141 (2006).

93. S. Marchand, M. Chenel, I. Lamarche, C. Pariat, and W. Couet. Dose ranging pharmacokinetics and brain distribution of norfloxacin using microdialysis in rats. J. Pharm. Sci. 92:24582465 (2003).

94. S. Marchand, A. Forsell, M. Chenel, E. Comets, I. Lamarche, and W. Couet. Norfloxacin blood-brain barrier transport in rats is not affected by probenecid coadministration. Antimicrob. Agents Chemother. 50:371-373 (2006).

95. M. E. Morgan, D. Singhal, and B. D. Anderson. Quantitative assessment of blood-brain barrier damage during microdialysis. J. Pharmacol. Exp. Ther. 277:1167-1176 (1996).

96. I. Westergren, B. Nystrom, A. Hamberger, and B. B. Johansson. Intracerebral dialysis and the blood-brain barrier. J. Neurochem. 64:229-234 (1995).

97. D. R. Groothuis, S. Ward, K. E. Schlageter, A. C. Itskovich, S. C. Schwerin, C. V. Allen, C. Dills, and R. M. Levy. Changes in blood-brain barrier permeability associated with insertion of brain cannulas and microdialysis probes. Brain Res. 803:218-230 (1998).

98. B. Davies and T. Morris. Physiological parameters in laboratory animals and humans. Pharm. Res. 10:1093-1095 (1993).

99. R. F. Reinoso, B. A. Telfer, and M. Rowland. Tissue water content in rats measured by desiccation. J. Pharmacol. Toxicol. Methods 38:87-92 (1997).
100. U. Bickel, O. P. Schumacher, Y. S. Kang, and K. Voigt. Poor permeability of morphine 3-glucuronide and morphine 6glucuronide through the blood-brain barrier in the rat. J. Pharmacol. Exp. Ther. 278:107-113 (1996).

101. W. B. Sisson and W. H. Oldendorf. Brain distribution spaces of mannitol-3H, inulin-14C, and dextran-14C in the rat. Am. J. Physiol. 221:214-217 (1971).

102. Q. R. Smith, Y. Z. Ziylan, P. J. Robinson, and S. I. Rapoport. Kinetics and distribution volumes for tracers of different sizes in the brain plasma space. Brain Res. 462:1-9 (1988).

103. R. P. Shockley and J. C. LaManna. Determination of rat cerebral cortical blood volume changes by capillary mean transit time analysis during hypoxia, hypercapnia and hyperventilation. Brain Res. 454:170-178 (1988).

104. M. M. Todd, J. B. Weeks, and D. S. Warner. Microwave fixation for the determination of cerebral blood volume in rats. J. Cereb. Blood Flow Metab. 13:328-336 (1993).

105. W. M. Pardridge and G. Fierer. Blood-brain barrier transport of butanol and water relative to N-isopropyl-p-iodoamphetamine as the internal reference. J. Cereb. Blood Flow Metab. 5:275-281 (1985).

106. E. Johansson, S. Mansson, R. Wirestam, J. Svensson, J. S. Petersson, K. Golman, and F. Stahlberg. Cerebral perfusion assessment by bolus tracking using hyperpolarized 13C. Magn. Reson. Med. 51:464-472 (2004).

107. E. M. Cornford, S. Hyman, M. E. Cornford, E. M. Landaw, and A. V. Delgado-Escueta. Interictal seizure resections show two configurations of endothelial Glut1 glucose transporter in the human blood-brain barrier. J. Cereb. Blood Flow Metab. 18:2642 (1998).

108. M. W. Bradbury. The Concept of a Blood-Brain Barrier, Wiley, Chichester, 1979.

109. A. Gjedde and O. Christensen. Estimates of Michaelis-Menten constants for the two membranes of the brain endothelium. J. Cereb. Blood Flow Metab. 4:241-249 (1984).

110. V. A. Levin, J. D. Fenstermacher, and C. S. Patlak. Sucrose and inulin space measurements of cerebral cortex in four mammalian species. Am. J. Physiol. 219:1528-1533 (1970).

111. D. L. Woodward, D. J. Reed, and D. M. Woodbury. Extracellular space of rat cerebral cortex. Am. J. Physiol. 212:367-370 (1967).

112. C. Nicholson and J. M. Phillips. Ion diffusion modified by tortuosity and volume fraction in the extracellular microenvironment of the rat cerebellum. J. Phys. 321:225-257 (1981).

113. N. H. Bass and P. Lundborg. Postnatal development of bulk flow in the cerebrospinal fluid system of the albino rat: clearance of carboxyl-(14 C)inulin after intrathecal infusion. Brain Res. 52:323-332 (1973).

114. H. Davson and M. B. Segal. Physiology of the CSF and BloodBrain Barrier, CRC Press, Boca Raton, 1995.

115. H. Suzuki, Y. Sawada, Y. Sugiyama, T. Iga, and M. Hanano. Saturable transport of cimetidine from cerebrospinal fluid to blood in rats. J. Pharmacobio-Dyn. 8:73-76 (1985).

116. P. P. Harnish and K. Samuel. Reduced cerebrospinal fluid production in the rat and rabbit by diatrizoate. Ventriculocisternal perfusion. Invest. Radiol. 23:534-536 (1988).

117. H. Cserr. Potassium exchange between cerebrospinal fluid, plasma, and brain. Am. J. Physiol. 209:1219-1226 (1965).

118. D. Wu, Y. S. Kang, U. Bickel, and W. M. Pardridge. Bloodbrain barrier permeability to morphine-6-glucuronide is markedly reduced compared with morphine. Drug Metab. Dispos. 25:768-771 (1997).

119. H. Duvernoy, S. Delon, and J. L. Vannson. The vascularization of the human cerebellar cortex. Brain Res. Bull. 11:419-480 (1983). 